\title{
EL REY EN LA CONSTITUCIÓN DE 1978: EL COMETIDO DE LA MONARQUÍA EN UNA DEMOCRACIA CON PRETENSIÓN DE VERACIDAD
}

ELOY GARCÍA 
SUMARIO

I. ¿ES POSIBLE UN REY EN DEMOCRACIA? A. La monarquía como absurdo democrático, sus sinrazones en una sociedad igualitaria. B. Legitimidad y credibilidad, de la Monarquía en el actual momento democrático español. C. La Monarquía en una Constitución que emergió como «logro evolutivo». II. LA MONARQUÍA PARLAMENTARIA ESPAÑOLA EN SU SIGNIFICACIÓN CONCRETA. A. Monarquía y modernidad política: legitimidad e identidad de la Monarquía. 1. El rey como institución vitalicia y hereditaria. 2. El rey como expresión de un Estado que monopoliza lo político. 3. Los deberes del rey neutral en una Constitución democrática. III. ESTRUCTURA Y FUNCIONALIDAD DEMOCRÁTICA DE LA MONARQUÍA. A. La abdicación como mecanismo de responsabilidad extraordinaria y el estatus constitucional del rey. B. Los actos del monarca en relación con los otros órganos constitucionales. El artículo 99 de la Constitución. 


\title{
EL REY EN LA CONSTITUCIÓN DE 1978: EL COMETIDO DE LA MONARQUÍA EN UNA DEMOCRACIA CON PRETENSIÓN DE VERACIDAD ${ }^{1}$
}

\author{
ELOY GARCÍA \\ Catedrático de Derecho Constitucional \\ Universidad Complutense ${ }^{2}$ \\ «The Revolution (1688)... for a long time \\ blated the generous feelings of loyalty ... Now \\ ... by the benignat effect of time the present \\ royal family are estabilishet in our affections." \\ («La Revolución (de 1688) ha tenido \\ por efecto sustituir el antiguo y generoso sen- \\ timiento de lealtad hacia la familia real, $y$ \\ establecerlo en la querencia que se le profese.»\}.
}

Boswell, Vida de Samuel Johnson. Londres 1791. Anotación del 23 de marzo de 1783.

Para Germán Fernández Farreres, en tributo a una amistad que ha resistido pruebas difíciles

\footnotetext{
${ }^{1}$ Este trabajo recoge sólo una pequeña parte del escrito elaborado para soportar la exposición oral defendida ante la comisión que presidida por el profesor Francisco Fernández Segado e integrada por los profesores Piedad García-Escudero, Ángela Figueruelo, Carlos Vidal y Josefa Ridaura, el 22 de mayo de 2019, revalidó mi condición de Catedrático; a ellos mi agradecimiento. Por tratarse de una selección parcial deja fuera numerosas cuestiones que fueron abordadas en el texto inicialmente preparado y que serán objeto de ulteriores publicaciones. En cualquier caso hay que dejar constancia que este trabajo se enmarca en el ámbito de los estudios y debates de la Cátedra de la Monarquía Parlamentaria, que con tanta «sagesse» dirige el profesor Juan José Laborda.

${ }^{2}$ Departamento de Derecho Constitucional. Facultad de Derecho. Universidad Complutense de Madrid. Ciudad Universitaria s/n. 28040 Madrid. Email: eloy.garcia@der.ucm.es
} 


\section{I. ¿ES POSIBLE UN REY EN DEMOCRACIA?}

\section{A. La monarquía como absurdo democrático, sus sinrazones en una sociedad igualitaria}

La primera impresión que estalla a bote pronto cuando se estudia la figura del monarca en la Constitución Española de 1978 (art. 56. y ss.), es su flagrante in-credibilidad, su no «reasonableness» en la acepción que Locke concede al término. Esto es su casi nula verosimilitud, la muy difícil —impensable — plausibilidad de la Monarquía como fenómeno flagrantemente insólito en los tiempos que corren. Objeción que aparece asociada a su inadmisibilidad lógica en el terreno de los principios, es decir, a su cuestionamiento como concepto abstracto susceptible de ser invocada legítimamente en una época en que su antagonista, el principio democrático, se ha impuesto de manera tan arrebatadora que incluso uno de los puntos de debate del presente, gira en torno a si hemos entrado o no en la fase de su superación y declive terminal (post-democracia).

$\mathrm{Y}$ es que parece obvio que en un mundo en que (como anunciaran Constant y Tocqueville) la igualdad se ha convertido en cimiento constitutivo del existir colectivo, nada puede resultar más repugnante que un monarca que accede a la Corona (que según recuerdan Fernando Rey o Jesús García Torres no deja de ser un órgano constitucional directo ${ }^{3}$ ) en virtud de las reglas de la herencia; el injuriante principio dinástico que restringe la transmisión de la Jefatura del Estado a la familia Borbón ${ }^{4}$. El solo tenor del artículo 57 de la Constitución: «La Corona de España es hereditaria entre los sucesores de su majestad don Juan Carlos I de Borbón»" ${ }^{5}$ levanta escalofríos por cuanto hay en él de privilegio injusto y de discriminación odiosa que ofende gravemente la razón democrática, el ejemplo de lo que Condorcet en su De la République ou

3 Es Jellinek quien insiste particularmente en la condición de reglas de derecho público de las normas de sucesión. Ver Teoría General del Estado, Madrid, 1956, pág. 604. Citado por García Torres, J. y Requejo, J. L., «La sucesión a la Corona», en Aragón, M., Temas Básicos de Derecho Constitucional II, Madrid 2011, pg 45 y ss, y Fernando Rey «Derecho de Sucesión en la Corona y discriminación por sexo: análisis de la posible supresión de la preferencia sucesoria de los varones», en Rubio Llorente, F. y Álvarez Junco, J. El informe del Consejo de Estado sobre la Reforma Constitucional. Madrid 2006, págs. 403 y ss.

4 Insiste especialmente en su condición de excepción al art. 14 que afirma el derecho a no ser discriminado, Miguel Satrústegui «La Corona», en López Guerra, L. y otros Derecho Constitucional, Tomo II, Valencia, 2000, pág. 32. Desarrolla en detalle el tema de la relación entre igualdad y sucesión en la primera parte de su trabajo Manuel Fernández-Fontecha, «Algunos problemas derivados de la posible reforma del artículo 57.1 de la Constitución», en Rubio Llorente, F., Álvarez Junco, J., El informe del Consejo de Estado sobre la Reforma Constitucional. Madrid, 2006, págs. 297 y ss

5 Existe una amplia bibliografía al respecto entre la que cabe recordar a Ramón López Vilas «La sucesión a la Corona. Comentario al art. 57 de la Constitución» en Lucas Verdú, P., La Corona y la Monarquía parlamentaria en la Constitución de 1978. Madrid, 1983, págs. 129-149. Este tema ha sido estudiado desde muy pronto por Gómez Sánchez. Vid., entre sus últimas aportaciones, «La sucesión a la Corona», en Rollnert Liern, G. (coord.), Las monarquías europeas en el siglo XXI, 2007, págs. 147-178. 
Un roi est-il nécessaire à la conservation de la liberté? llamaba «superstición impía que hacía de un hombre una suerte de divinidad» ${ }^{6}$.

Al absurdo de abogar en favor de la Monarquía desde la lógica sociológico-credencial de un Estado que radica su piedra de toque en el binomio democracia/igualdad social, habría que añadir desde la Teoría Constitucional el escepticismo y los reparos que entre una cualificada doctrina despierta el nulo peso y la intrascendencia de las atribuciones que la Constitución confía al Rey como Jefe del Estado, que en régimen parlamentario (art. 1.3 CE) son siempre de tipo relacional y comunicativo, lo que desemboca en su extinción como órgano y en la atribución de sus tareas a las restantes instancias constitucionales.

De aquí surge un tercer argumento crítico, expuesto entre nosotros hace ya muchos años por el profesor Pérez Royo, encaminado más a cuestionar la racionabilidad funcional de la Jefatura del Estado en los regímenes parlamentarios que expresamente dirigido a objetar al monarca, por mucho que haya sido esgrimido para desautorizar a una magistratura que resulta difícilmente imaginable en términos democráticos e igualitarios ${ }^{7}$. Se

${ }^{6}$ El discurso de Condorcet es la primera y mejor expresión de la idea republicana en la Democracia de los modernos y sus argumentos poseen una fuerza descomunal cuyo eco llega hasta nuestros días. Desde un punto de vista de construcción intelectual el enfrentamiento monarquía y la propia definición de la Monarquía conocen tres momentos: uno, primero, marcado por la defensa de un trono asentado en la sociedad y compatible con las nuevos tiempos como factor de estabilidad de una sociedad que aspira a conservar el orden existente, sin que ello supusiera negarse a evolucionar, representado por Mounier en sus Considérations sur les Gouvernements et principalment sur celui qui convient à la France de 1789 y sobre el que luego se edificaran los argumentos y, no la praxis, del Principio monárquico. Otro segundo que aparece como tal en el momento de la fuga del rey y cuyos extremos polémicos son el citado discurso de Condorcet y la réplica de Sieyes en Le Moniteur en que defiende una «república monárquica» y otro tercero que arranca del fracaso práctico de la propuesta del monarca electo de Sieyes (y que tiene como resultado la experiencia napoleónica) cuyo exponente es Benjamín Constant y su doctrina del «rey neutral» que llega a nuestros días.

7 Desde el punto de vista conceptual más estricto y teniendo en cuenta que nuestras categorías jurídicas derivan del derecho romano, no sería correcto emplear el término magistratura para referirse a la monarquía por su origen no democrático y su condición vitalicia. En este sentido, basta acudir al testimonio de Mommsen para entender que estamos ante un significante que el derecho de Roma reservaba con carácter exclusivo a las instituciones republicanas. El término magistrado se trae a colación solo de la persona que porta un mandato del pueblo y en consecuencia no es predicable del viejo rey, ni de las instituciones religiosas romanas. En ese sentido véase Theodore Mommsen, Le Droit Publique Romaine. París, 1892, Tomo I, pág. 1 y ss. Sin embargo en el lenguaje normal de nuestros días para referirse al rey se utiliza indiscriminadamente las expresiones institución o magistratura (ver voz magistratura en diccionario RAE), prueba evidente de que la conciencia colectiva no se diferencia ya de manera clara entre monarquía y república. Y es que como enseñan Pocock y en general los autores de la escuela de Cambridge, los cambios semánticos inconscientes preceden siempre en el tiempo a los cambios formales y deliberadamente conscientes. En este sentido y como prueba de la contaminación y disglosia lingüística-política entre monarquía y republica a que estamos asistiendo, baste traer a colación la siguiente referencia que forma parte de Acta por la que el anterior rey abdica el trono, y en la que se dice: «Por todo ello, guiado por el convencimiento de prestar el mejor servicio a los españoles y una vez recuperado tanto físicamente como en mi actividad institucional, be decidido poner fin a mi reinado y abdicar la Corona de España, deponiendo en manos del Gobierno y de las Cortes Generales mi magistratura y autoridad para que provean a la efectividad de la sucesión en la Corona conforme a las previsiones constitucionales. » Preámbulo de la L. O. 3/ 2014 de 18 de junio por la que se hace efectiva la abdicación de S.M. el rey Juan Carlos I.

N. ${ }^{\circ} 105$, mayo-agosto 2019, págs 19-55 
trata de un argumento que sostiene que en el modelo parlamentario la Jefatura del Estado se configura como una instancia decorativa o ceremonial cuya insuperable in-sustantividad termina abocando a una extinción forzosa. Nos encontramos ante la versión actual del «roi fainéant» que rechaza la utilidad de la magistratura rey/jefe del Estado argumentando desde su falta de eficiencia: el rey no tiene nada que hacer y es perfectamente prescindible ${ }^{8}$.

Sin embargo, la tesis de la irrelevancia sustancial de la Jefatura del Estado en los regímenes parlamentarios, no resulta compartida ni por la mayoría de la doctrina comparada —y baste citar la sólida monografía Die Funktionen des Staatsoberbauptes in der parlamentarischen Demokratie de Werner Kaltefleiter ${ }^{9}$ - , ni por los textos constitucionales de las democracias parlamentarias, que con pocas excepciones recogen ciertas funciones indeclinables que corresponden exclusivamente al jefe de Estado, con independencia de que su titularidad sea o no de una testa coronada.

De cualquier forma, hay que tener en cuenta que esta investigación no está dirigida a dilucidar problemas de Teoría Constitucional sino a manejarse en la realidad constitucional española para determinar si un órgano constitucional cumple o no una función que resulte útil y aprovechable (funcional) al conjunto del sistema. Es así como sólo desde el estudio de la atribución de conectar y relacionar entre sí los «órganos constitucionales de soberanía», representando y expresando simultáneamente la continuidad de la política (al Estado), se puede apreciar si la función atribuida al rey reviste una importancia palpable y utilidad tangible en la vida democrática española.

En suma, nuestra investigación va dirigida a abordar cuestiones concretas de derecho español y no a enunciar modelos teórico-especulativos que operen como de

${ }^{8}$ Así lo hace implícitamente Constant en la lectura que defiende Javier Pérez Royo en su trabajo «La Jefatura de Estado en la Monarquía y en la República» en Lucas Verdú, P., La Corona y la Monarquía citado, págs. 85 y ss. Critica Pérez Royo, en un meritorio trabajo donde por primera vez incorporará en la doctrina española las aportaciones de los Fragmentos de Constant, la irrelevancia de la Jefatura del Estado hasta el extremo de, indirectamente, proponer suprimirla.

La tesis de la insignificancia está también en la cultura popular que a menudo se pregunta si sus funciones son decorativas ¿para qué sirve un rey? Como veremos más adelante esta tesis se corresponde con un entendimiento del neutralizado del monarca en el que el peso de la Corona es nulo. En nuestro modelo constitucional, el Jefe del Estado tiene una función efectiva, es decir dotada de contenido, por eso justamente hay que explicarla, y por eso también — dicha sea de paso — el monarca se define como neutral. Lo más cercano al monarca neutralizado sueco que existe en la jefatura republicana es el Presidente alemán que, no obstante tiene atribuidas algunas competencias.

9 «Hay dos tareas que resultan comunes al jefe del Estado en todas las formas de gobierno: articular consenso constitucional y propiciar, apoyar y sobrellevar el «encauzamiento» (Arbeittsfäbigkeit) (que asimismo puede traducirse por potenciación de la mecánica, de la buena marcha, o del desarrollo de los demás órganos constitucionales) del sistema democrático. Al respecto de ambas funciones, la Jefatura del Estado también necesita de cierto apoyo de todas las agrupaciones políticas en general y del reconocimiento de su imparcialidad y neutralidad de su obrar en el sentido de que todos los grupos entiendan que tal facultad e influencia no presupone la imposición de ningún tipo de exigencias a los actores políticos», Kaltefleiter, W., Die Funktionen des Staatsoberhauptes in der parlamentarischen Demokratie. Colonia 1970, pág. 198. 
Procusto de nuestra realidad constitucional. Y este es el esquema que seguiremos como guía de la exposición, porque dónde hoy sitúa la doctrina la vexata quaestio es en saber sí, como consecuencia de la racionalización de la política que implica la democracia (Manuel Aragón y Enrique Belda ${ }^{10}$ ), las funciones inmanentes al jefe del Estado pueden ser desempeñadas de manera más o menos equiparable por una magistratura republicana y por otra monárquica, y qué tipo de ventajas contrastables acompañan a una y a otra.

En esta misma línea y como cuarta objeción a la viabilidad de la monarquía hay que apuntar el afán de regenerar las instituciones constitucionales que ha puesto sobre la mesa un argumento recubierto del ropaje de lo novísimo pero impregnado de la vieja hostilidad hacia la monarquía forjada en la cultura republicana clásica: el rey cómo binario ideológico de la República, incompatible con el gobierno del pueblo (Democracia). Es así, como una parte considerable de nuestra sociedad ha situado sobre el tablero la urgencia de derrocar la Monarquía y de reemplazarla por una República. Un cambio de régimen que para muchos añadiría un beneficio democrático de envergadura: acometer la labor que la Transición no fue capaz de abordar y que todavía obstaculiza una soberanía popular plena. Un legado franquista aún no liquidado y que continúa lastrando nuestro quehacer cotidiano porque la monarquía parlamentaria contiene notables dosis del germen que ha contaminado la democracia y propiciado la degradación de nuestro sistema constitucional (Javier Pérez Royo).

Se trata de un argumento formidable en contra de la Monarquía que, más allá de su procedencia con su sola evocación mancha el renqueante prestigio democrático de la Corona, al tacharla de heredera del franquismo, postrero exponente de un régimen de facto históricamente periclitado. La improcedencia de la Monarquía, pues, como expresión ideológica de un régimen anti-democrático que, a sensu contrario, la República per se sí trae indefectiblemente consigo ${ }^{11}$.

${ }^{10}$ La tesis de la racionalización que supone la monarquía ha sido defendida especialmente por Manuel Aragón Reyes desde hace años en numerosos trabajos, por citar uno de los primeros, Dos estudios sobre la Monarquía Parlamentaria en la Constitución Español. Madrid, 1990. Así mismo y desde otra perspectiva el estudio de Enrique Belda, ¿Qué le falta a la monarquía española para estar plenamente racionalizada?: (la monarquía española del siglo XXI). Valladolid, 2015. En general, sobre la monarquía en España, vid. VV.AA., La Monarquía Parlamentaria (Título II de la Constitución), Congreso de los Diputados, Madrid, 2001.

${ }^{11}$ Entre la literatura científica española que se ha dedicado a estudiar la República como régimen opuesto a la Monarquía sólo conocemos el libro de Carlos de Cabo, La República y el Estado Liberal. Madrid, 1977, que resume su tesis doctoral, y que repudia claramente la República como instrumento de dominación de clases. Literalmente apuntaba el profesor Carlos Ollero en su prólogo-resumen como presupuesto fundamental de la obra: «Señalar la coincidencia histórica entre la imposición del modo de producción capitalista y la aparición de la republicas. ... La República suministró el aparato ideológico e institucional adecuado a la configuración del Estado en esta fase de desarrollo capitalista». Es posible que entre esta postura y la actual urgente necesidad de la República que propugna este autor en repetidas conferencias y disertaciones académicas, medie algún otro trabajo que haya pasado desapercibido y que justifique tan insólito cambio de rumbo. 
Anticipándose a estas aseveraciones, algunos de nuestros más reputados estudiosos llevan tiempo advirtiendo que el fundamento último de la monarquía reposa sólo y estrictamente, en la Constitución y en los consensos democráticos que la construyeron, entre los que la Corona ocupa una posición preferente garantizada por el mecanismo de la revisión total (art. $168 \mathrm{CE}$ ). Según esta postura, auspiciada entre otros por los profesores Antonio Torres del Moral o Francesc de Carreras ${ }^{12}$, cuestionar la Monarquía equivaldría poco más o menos que a objetar la normatividad que ha permitido el periodo más largo de estabilidad constitucional que hemos conocido y traería consigo la apertura de un proceso en el que se pudieran reabrir los grandes problemas de España. La normatividad y el derecho constitucional aparecen de esta manera como justificación por antonomasia de la Corona $^{13}$, lo que lleva aparejado que sea la Constitución la que legitime democráticamente una magistratura cuya explicación definitivamente no puede radicar en una tradición histórica — paradójicamente ahistórica ${ }^{14}$ — , que desde hace años viene defendiendo el profesor Herrero de Miñón.

${ }^{12}$ El profesor Antonio Torres posiblemente sea el autor que más se ha ocupado entre nosotros de la Monarquía, por citar alguno de sus más pioneros trabajos, véase, «La monarquía parlamentaria como forma política del estado español», en Lucas Verdú, La Corona y la Monarquía parlamentaria en la Constitución de 1978, citado, págs. 39-84; «La Corona» en Revista de Derecho político, N. ${ }^{\circ} 36,1992$, págs. 303 y ss. Asimismo, ha coordinado la muy relevante obra Monarquía y Constitución, Madrid, 2001, en la que se recogen numerosos trabajos que deben ser tenidos en cuenta. Por su parte, Francesc de Carreras, «El significado Constitucional de la Monarquía Parlamentaria», en Tusell y otros La Corona en la Historia de España. Madrid 2003, pág 26 y ss.

${ }_{13}$ Para salvar el hiato entre democracia y tradición como legitimidades incompatibles muchos autores como Rodríguez-Piñero insisten en el carácter hereditario de la Corona pero lo contrapone a la legitimidad constitucional, expresión a su vez de la idea democrática. Es algo así como si la idea de soberanía popular que fundamenta la Constitución fuera el hecho nuevo que rompiendo con la ilegitimidad democrática de la herencia, borra el pasado y confiere pedigrí democrático a la monarquía. A partir de ese momento la Corona es tan democrática como la Constitución y cualquier juicio sobre su legitimidad pasa a ser un juicio sobre su constitucionalidad. Rodríguez-Piñero, M., Comentarios a Constitución Española, Madrid, 2018 (Art. 56).

${ }^{14}$ La tesis historicista pero en el fondo ahistórica defendida por Miguel Herrero por primera vez en su libro El Principio Monárquico, Madrid, 1972, y reiterada luego en todos sus trabajos de manera inalterada hasta nuestros días, adolece de una falta de concreción histórica en la medida en que no especifica de qué momento concreto deriva la Monarquía española su historicidad, ¿de don Pelayo? Y mucho menos explica el fundamento actual que soporta. Así, por ejemplo en «La posición constitucional de la Corona (art. 57)», en El valor de la Constitución, Madrid, 2003. "La Monarquia es, sin duda, la piedra angular de la historia de España y lo es de su presente... hoy es elemento clave de ... nuestra Constitución sustancial... La Corona no es una creación de la Constitución, sino que la asume como realidad pre y para constitucional cuya potencia política excede a la racionalidad jurídica....» (págs 236 y ss.) Escarbando un poco en su argumentación, detrás de esa continuidad defendida por Herrero se entrevé una tesis que en 1972 pretende dotar de legitimidad a una institución por venir que vive inmersa en un mundo de ilegitimidad; algo similar a lo que, como demuestra Barthélemy en su importante estudio «Les Théories royalistes dans la doctrine allemande contemporaine» (Revue du Droit Public, T. XXII, pág. 47 y ss), sucedería en el mundo germánico tras la Restauración, en el que la doctrina del Principio monárquico fue un injerto artificial para encubrir la fuerza de las bayonetas que contenía los avances de la igualdad democrática. En 
Pero más allá de lo que hipotéticamente pudiera delatar el intento de reducir el problema de la obediencia a una cuestión de auto-organización política, semejante fundamento comporta dos inconvenientes: uno, que resuelve el debate a fuerza de confundir legalidad con legitimidad; dos, que diluye el problema de la utilidad operativa y democrático-funcional de la Monarquía como institución concreta en la gran cuestión del funcionamiento general del sistema y evita cualquier comparación práctica con una magistratura republicana que es el referente inexcusable para entender la funcionalidad o no-funcionalidad de la monarquía.

En relación con lo primero, soportar argumentalmente la Monarquía en la legitimidad que emana de la Constitución, lleva a ver en la Constitución una suerte de punto de encuentro omnicomprensivo entre normatividad constitucional y voluntad colectiva, que se expresa en forma de Poder Constituyente y que sitúa su motor de arranque en un momento fundacional. Es el esquema de la Constitución revolucionaria que responde a la idea de un momento creador previo que lo ordena e instituye todo a través de un hecho instaurador que origina un Tiempo nuevo. Estamos ante un modelo predicable de los Estados Unidos en la Revolución de 1776, o Italia y Alemania, en 1947 y 1949, o incluso la España de 1931, que rompieron hobbesianamente con el pasado e inauguraron una era que arranca de la legitimidad que opera como pars construens de la convivencia colectiva. Pero también ante un modelo que difícilmente resulta predicable de una experiencia como la española de 1978, en la que la Constitución —como anticipara Luis García San Miguel en 1969 ${ }^{15}$ — acredita ser una «adquisición evolutiva» — para tomar los términos de Niklas Luhmann ${ }^{16}$ que no conoce ningún comienzo legitimador sino que existe tan sólo en cuanto procedimiento de tránsito continuado en el que no se conocen rupturas, ni normas o realidades definitivas y acabadas.

Ello no obstante y más allá de cualquier consideración acerca de cuál haya podido ser en el caso español, el papel de la normatividad constitucional como factor legitimante-instaurador de la monarquía, a lo que nuestro planteamiento conduce es a no sobrecargar la Constitución olvidando que las instituciones responden a una raciona-

nuestro caso, por aquellos días la fuerza de las armas franquista declinaba, al tiempo que comenzaba a brillar en el horizonte la futura magistratura monárquica que, encaramada en la persona del entonces Príncipe Juan Carlos, no sabía bien cómo afrontar su destino, motivo por el cual solicitaba habitualmente a todo personaje ilustre que lo visitaba un «papel» que pusiera negro sobre blanco lo que debería hacerse el día que se cumplieran las previsiones sucesorias. Nadie sabe qué fue de aquellos informes que numerosas personas se apresuraron a hacer llegar la Zarzuela, pero el trabajo de Herrero —y es sólo una hipótesis - tiene toda la pinta de haber sido originariamente uno de ellos.

${ }^{15}$ García San Miguel, L., «Estructura y cambio del régimen político español» en Sistema, n. ${ }^{\circ} 1$, Madrid, págs. 81 y ss.

${ }^{16}$ Luhmann, N., «Verfassung als evolutionäre Errungenschaftin» Rechtshistorisches Journal, 1990, p. 178. Significativamente traducido al francés, italiano e inglés y no al español. Para Luhmann la novedad que cabe atribuir a la Constitución que aparece en el siglo XVII, es su capacidad de integrar derecho y política construyendo por un lado un espacio para una «política del derecho» y por otro para un «derecho de la política». 
lidad intrínseca que les confiere su cometido funcional y que en momentos de convulsión y declive social, es su arraigo medioambiental y su coherencia funcional interna quien salva o quiebra su continuidad y necesidad política y por ello constitucional. Algo que no puede hacer a un estatus jurídico-positivo que difícilmente consigue auto-justificarse a sí mismo por mucho que sea clave para su pervivencia en el día a día.

En conclusión, un pronunciamiento en favor de la monarquía en una comunidad democrática reclama una explicación realista e incluso se encuentra necesitado de una legitimación que la Republica no requiere en la medida que viene automáticamente reconocida como corolario obligado de la idea imperante en nuestra época, la igualdad democrática. Pero también quien aspire a defender la vigencia de la Monarquía en una sociedad del siglo xxi tendrá que efectuar un esfuerzo argumental adicional que, asuma la carga de la prueba de su mejor funcionalidad comparativa práctica y la articule desde la utilidad operativa de una magistratura que se encuentra en condiciones de insuflar tanta o más credibilidad al conjunto del sistema institucional que una jefatura republicana. Y no estamos confundiendo categorías porque aunque no es posible hablar de credibilidad allí donde no existe legitimidad, sí caben niveles diferentes de credibilidad — incluso uno marcado por su total y enmascarada ausencia como es el simulacro- en un régimen plenamente legítimo en términos democráticos. La legitimidad es una aceptación que a falta de alternativas en conflicto muy bien puede quedar reducida a mera inercia pasiva. La credibilidad se proyecta siempre necesariamente en clave de definición positiva y activa: sólo es creíble aquello que los hechos demuestran (acreditan) con su quehacer que resulta auténtico, en el sentido de resultar socialmente veraz y no mendaz. Aquello que a través de la fuerza de su realidad efectiva - o con la narrativa que generan sus acontecimientos - no aspira a dar a entender algo que en verdad no es. La legitimidad es una categoría sociológica de índole fundamentalmente política, la credibilidad también es una categoría sociológica pero de naturaleza marcadamente psicológica. La legitimidad enfatiza y busca lo objetivo, la credibilidad edifica sobre lo subjetivo. La legitimidad procura un orden compartido, la credibilidad depara un conocimiento plausible. La una es doctrina oficial compartida, la otra, convencimiento o sentimiento íntimo. Una tiene sus fuentes en la lectura de los trabajos o panfletos de los Étienne de La Boétie, Pascal y Benjamín Constant, y otra se conforma en torno a los pensamientos e inquietudes de los Locke, Leibniz o David Hume.

\section{B. Legitimidad y credibilidad, de la Monarquía en el actual momento democrático español}

Así pues, los anteriores pronunciamientos subestiman dos datos que si bien no son fruto de un razonamiento concebido para explicar la Monarquía, sí obran decididamente en su favor al clarificar el papel que le cumple desempeñar en la realidad constitucional y que permiten entender la exitosa supervivencia de la figura del monarca en ciertos Estados democráticos de naturaleza parlamentaria —aunque no 
sea válida a nuestros efectos la demostración comparada. El primero hace mención al entendimiento de la legitimidad como una categoría cultural de plena proyección práctica y no como principio abstracto o enunciado ideal, mientras que el segundo se construye desde el reconocimiento de la fuerza de los hechos como soporte de la vitalidad de las instituciones y de su operatividad y su pervivencia a través de un veraz cumplimiento de sus fines.

Por lo que hace al primero, hay que recordar que la categoría de legitimidad que manejamos no es una idea pura sino una atmósfera incorpórea y gaseosa que integra en una fórmula única una enorme multiplicidad de certezas y de valores gestados en ámbitos y al servicio de propósitos distintos (incluso antinómicos), y que tiene como resultado la obediencia social y el consentimiento del orden establecido. En la realidad efectiva de la política, la legitimidad no se configura morfológicamente como un postulado abstracto, y mucho menos como la derivada de un principio único sustancialmente puro nacido de un razonamiento teórico excluyente incompatible con cualquier otro rival, sino que - como sucede en la naturaleza con los compuestos químicos que siempre se presentan amalgamados - es el producto de incorporar en la fórmula ideológica que sostiene una determinada cultura política una multiplicidad de elementos procedentes de sustancias intelectuales y vitales distintas, que sirven para fundar y justificar la adhesión de una sociedad a su particular estructura de gobierno.

La legitimidad no es una identidad pura, sino el producto de una confluencia de identidades muy diferentes que por el hecho de confluir, renuncian a su pureza esencial y se disuelven en una fórmula integradora. En este sentido la fórmula de legitimidad que justifica el orden de una determinada comunidad es el resultado de la particular evolución de la propia sociedad, de unas circunstancias que son siempre específicas y se expresa como una suma acumulada de factores idiosincráticos que no conoce más punto de coincidencia que la comunidad a la que integra y da consistencia. La legitimidad de una sociedad histórico-concreta es un producto complejo en la que convergen elementos procedentes de aquello que Weber llamaba tipos ideales de legitimidad o, dicho de otra forma, principios que en el laboratorio de un científico de la política se ofrecen como datos ontológicamente puros. La realidad de la legitimidad (el tipo evolutivo de legitimidad del que habla Otto Hintze) no conoce el imperio de un principio único a secas, porque en la política de cada momento confluyen materiales de muy distinta factura, modelados sobre circunstancias también distintas y no siempre ordenados en términos lógico-jerárquicos. Es bien cierto que dentro de toda fórmula de legitimidad subyace un factor dominante, pero también que ese elemento convive con otros qué siendo cualitativamente menos destacados, coadyuvan operativamente a su funcionalidad, aunque desde el punto de vista de la teoría parecieran no ser compatibles. Así sucedía, por ejemplo, en las monarquías absolutas en las que la legitimidad aristo-monárquica coexistía con viejas conformidades religiosas que divinizaban al príncipe o con otras reglas de origen feudal o también, en la fallida experiencia napoleónica, dónde Bonaparte intentó articular una 
estructura de legitimidad que incorporaba supuestos procedentes de la legitimidad republicana, la carismática o de la monárquica, combinados todos ellos con el soporte que le suministraba las bayonetas de un ejército victorioso. La legitimidad no se presenta en la realidad en términos de tipo puro y nada tiene de extraño que naciones de inobjetable definición democrática alberguen en su fórmula de legitimidad componentes no propiamente democráticos, en el sentido de no derivados del principio teórico de la democracia, que, sin embargo, resulten funcionales a la política democrática en un régimen parlamentario. Uno de ellos muy bien puede ser la monarquía, como se observa en Gran Bretaña, los Países Bajos o Bélgica, o en nuestro mismo país, España. Y es que la fórmula de legitimidad democrático-constitucional es una integración de elementos intelectuales y estructural-sociales que van más allá del simple sufragio igual, por muy preponderante y relevante que este pueda resultar. Por lo mismo resultaría también prácticamente inviable una teoría general de la monarquía que - a inspiración de la Allgemeine Staatslebre de Jellinek — pretendiera abarcar al conjunto de cabezas coronadas de las diferentes democracias conocidas. La monarquía es un avatar particular de cada Estado cuya lógica sólo puede ser comprendida y legitimada desde el medioambiente político en que se inserta. Y concretamente en la realidad constitucional española, el rey es una de las instituciones que más dependen de su funcionalidad y acierto cotidiano, que sustituye a la magia que informa la Corona inglesa. No sería desacertado decir, con el profesor Bastida, que la monarquía es la institución más «presentista» de cuantas recoge nuestra Constitución ${ }^{17}$. Su razón

17 Apunta esta idea Francisco Bastida en un artículo publicado en La Nueva España «¿El Gran Hermano en la Casa del Rey? La necesidad de regular por ley la abdicación, las renuncias o cualquier otra duda sobre la sucesión a la Corona», que no tiene desperdicio. «Por tanto, a la inviolabilidad del Rey se ha unido de facto la inviolabilidad de su Casa, como si ésta fuese sólo su domicilio particular. Para el Gobierno y la Mesa del Congreso de los Diputados fiscalizar las cuentas de la Casa Real equivale a fisgar en sus asuntos privados, invadiendo la intimidad del Rey y de su familia. Si alguna institución necesita de una transparencia extra esa es la monarquía y durante todos estos años no se ha hecho otra cosa que alimentar su opacidad y con ello la sensación de inmunidad, que es el mejor caldo de cultivo para creerse impunes. El Rey parece haberse olvidado de la máxima que le dijo a su hijo «La Corona se gana día a día». Nadie le negará a D. Juan Carlos su trascendental papel en la transición política, en el $23 \mathrm{~F}$ y como primer embajador de España, incluso su honradez en el gesto de pedir perdón por haber ido de cacería, cuando ningún político se ha dignado a hacer lo mismo por hechos bastante más graves. Pero el agradecimiento por los servicios prestados se oficializa cuando uno cesa en el cargo. Si alguna justificación tiene la monarquía en una democracia, ésa es la función que la Corona puede desempeñar en la representación y unidad del Estado, no en la función que desempeñó. No hay una monarquía de gratitud por el pasado, sino una monarquía de ejemplaridad por los servicios que presta. La pregunta es si en estos momentos el Rey está en condiciones de ofrecer esa jefatura ejemplar. Estamos en un episodio histórico en el que el cazador es cazado. Se ha levantado la veda y el Rey, tan amante de cacerías de todo tipo, es ahora la pieza a batir. Los rastros a seguir son variados, amistades peligrosas, patrimonio acumulado, herencia, cuentas en Suiza y, para colmo, la imputación de su yerno Urdangarín y ahora de su hija Cristina por unos negocios basados en el tráfico de influencias. El nombramiento de Miquel Roca como abogado de la Infanta es una opción de alto riesgo, primero por la implicación directa del Rey en la organización de la defensa judicial de su hija y, después, porque la elección de Roca, uno de los padres de la Constitución, no obedece a su valía como penalista, sino seguramente por su condición de hábil 
intelectual le exige una confirmación permanente a través de su efectividad funcional, a la que no puede renunciar so pena de dejar en evidencia la ofensa y los grandes absurdos estructurales en que se sostiene y que pudieran llevar al descubrimiento de una realidad inasumible ante los ojos abiertos que de repente comprueban asombrados «que el rey está desnudo». Pero lo importante es entender que en el mundo de las realidades fenomenológicas monarquía y fórmula de legitimidad democrática no son forzosamente incompatibles, como por el contrario lo son en el mundo de la abstracción ontológico-política. Porque la política que nos interesa, la dimensión de la política en que nos movemos es la praxis (Friedrich), la realidad concreta. Y en el plano de la praxis nadie puede negar la posibilidad de que una serie de Estados inobjetablemente democráticos sean Monarquías, en el sentido de estar organizados como democracias parlamentarias encabezadas por un rey. Todo depende de la racionabilidad interna que la Monarquía pueda deparar a la democracia, de la coherencia funcional que sea capaz de incorporar y de la aceptación que de ella haga la sociedad.

Poco a poco, nuestra argumentación se ha ido deslizando desde lo ontológico a lo fenomenológico, desde la contradicción entre principios característica de la visión de la Historia de las Ideas hasta un entendimiento de los problemas constitucionales organizado en el marco de los contenidos intelectuales (Historia intelectual) que los alimentan y que construyen sus argumentos que debe ser funcional. Y ello nos lleva a sostener que la legitimidad de la monarquía tiene que ser analizada prestando atención, no sólo a los componentes nucleares que en el terreno de los principios informan la existencia de tan singular magistratura (estructura), sino y sobre todo comprendiendo la funcionalidad de su posicionamiento en el conjunto de la fórmula de legitimidad en que se integra (función). Estamos ya en el supuesto de la credibilidad que deriva del correcto funcionamiento de la institución en sus hechos, un referente que hay que analizar para seguir adelante. $\mathrm{Y}$ para eso es necesario ponderar la sinceridad de los comportamientos del hombre que encarna la Corona y formular un juicio de veracidad sobre la magistratura, que corresponde emitir a la sociedad.

Como ha apuntado agudamente Ingolfur Blühdorn en un libro de referencia obligada — Simulative Demokratie. Neue Politik nach der postdemokratischen Wende de

\footnotetext{
negociador. Es cuestionable si llegado a este punto el Rey debería abdicar como un servicio más a su país, pero, de hacerlo, nos encontraríamos, como en el Vaticano, con un Rey emérito, desprovisto de su inviolabilidad, y por tanto judicialmente vulnerable, empezando por las demandas de reconocimiento de paternidad y siguiendo por todos aquellos actos privados realizados durante su mandato de los que pudieran derivarse alguna responsabilidad y que no hubiesen prescrito. Puede que a España le interese la abdicación, pero, desde luego, no al Rey. Los medios de comunicación han pasado del tabú de la Casa del Rey a querer tratarla como un Gran Hermano. La democracia exige transparencia, no un royalty show; el esclarecimiento de la verdad, no una lucha por audiencias a base de insinuaciones y rumores. Pero, por ahora, de lo único que nos enteramos con certeza es de quiénes van siendo expulsados de la Casa. El asunto no es divertido y, tal como están las cosas, el Gobierno y las Cortes deberían dejar de mirar la televisión y cumplir el mandato constitucional de regular por Ley orgánica la abdicación, las renuncias y cualquier duda de hecho o de derecho sobre la sucesión a la Corona». La Nueva España, 07.04.2013.
} 
2013 - , uno de los peligros más letales para la vida política democrática actual radica en un cumplimiento de las obligaciones que pretiriendo sus fondos aboque a una situación de democracia simulativa («simulative demokratie») más o menos generalizada, en el doble sentido de artificiosidad y de hipotético falseamiento de la realidad fáctica que se aparenta representar. Y es que una cosa es el cumplimiento formal de los cometidos asignados y otra muy diferente el respeto activo a los fines intelectuales materiales a los que se debiera responder. En el primer caso de lo que se trata es de respetar unas reglas de procedimiento, de cumplir la letra de la norma de la manera más escrupulosa posible. En el segundo, de perseguir efectivamente el fin a que responde la existencia de la institución, de orientar las conductas en coherencia con los hechos ateniéndose al espíritu que informa sus deberes. Y es que los hechos son la prueba más esclarecedora posible para calibrar la sinceridad de las actuaciones de una institución política y su viabilidad misma. Ello es particularmente pertinente en aquellas magistraturas que, como la monarquía, tienen por finalidad algo tan etéreo y a la vez tan concreto, como propiciar el juego político (la comunicación en el sentido que luego se explicitará) de las demás instancias públicas manteniendo la continuidad institucional, y lo llevan a cabo desde la acción personal, a través de la intervención de un ser de carne y hueso. Por eso la propia conducta del monarca no sólo tiene que ajustarse formalmente a la Constitución, sino que debe guiarse por un patrón articulado desde lo que se denominan obligaciones de responsabilidad personal inexcusable. Entramos en el terreno de figuras magistralmente estudiadas en la doctrina iusprivatista por Pablo Salvador Coderch $^{18}$, como la lealtad en los comportamientos, la confianza legítima y los deberes de responsabilidad in vigilando, que resultan especialmente agravados cuando su destinatario es un poder público que goza de una posición que aspira a encarnar a un Estado que integra a toda la sociedad. Y es aquí cuando aparece en juego la veracidad, que no es otra cosa que el resultado del contraste a que los hechos someten la conducta intencional de los sujetos que encarnan los órganos constitucionales en razón a su ininterrumpida sinceridad, esto es, a la existencia de una inalterada y fehaciente coherencia entre lo que se transmite y lo que efectivamente se hace en el ámbito de sus motivaciones, lo que implica proscribir la diferencia entre realidades y apariencias, entre intencionalidades y hechos, entre creación intelectual y realización material. Esa conducta reiterada en el tiempo, construye una conciencia en la sociedad sobre el veraz cumplimiento de las funciones encomendadas que sirve de parámetro de medición de la credibilidad de la institución. Una prueba que la monarquía debe superar si aspira a continuar viva y que de lograrlo muy bien pudiera terminar proyectando credibilidad — su propia credibilidad — al conjunto de la vida política, tornándola a su vez más auténtica.

18 Sobre este tema en el ámbito mercantil y penal, véase Salvador Coderch, P. y Silva Sánchez, J.M., Simulación y deberes de veracidad. Derecho civil y derecho penal: dos estudios de dogmática jurídica. Madrid, 1999. 
Para que no quede resquicio a ningún equívoco, conviene insistir en que la credibilidad no tiene fundamento en las urnas, ni deriva ni se muestra como expresión de cualesquier otro proceder democrático porque — como afirmaba Indro Montanelli- es perfectamente posible votar en favor de algo que no resulte creíble. Y es que la credibilidad consiste en la corriente de atracción positiva que se genera entre la sociedad en favor de una persona o una institución como resultado de su sincero y continuado interés en el cumplimiento de los cometidos de fondo a que está impelida. Un cumplimiento que al ser coincidente con sus fines materiales, se define en el juicio social como un comportamiento veraz que confiere vitalidad a la institución. Es de este comportamiento socialmente veraz de donde arrancan los indicios que dan vida a la credibilidad. En definitiva, la credibilidad consiste en una estima que no tiene que ver con la confianza política (trust) sino con la veracidad que la sociedad atribuye (o indiciariamente presume) en favor de un sujeto que por la autenticidad intelectiva de sus acciones se beneficia de una aceptación que se proyecta hacía el futuro. Esa credibilidad es radicalmente opuesta a lo que representa el simulacro, esto es, se configura como su antítesis y permite obtener en la sociedad un respaldo sustancialmente diferente y considerablemente más entusiasta y activo del que se alcanza a través del sólo respeto a las mecánicas y a los procedimientos formales. La vitalidad de una institución proviene de su percepción social como veraz y esa veracidad obra también como soporte de su credibilidad.

\section{La Monarquía en una Constitución que emergió como «logro evolutivo»}

De lo expuesto se desprende que tanto la legitimidad como la credibilidad tienen su encuadre en la sociedad, aunque se trate de supuestos estructural y categóricamente diferentes. Ambos son fenómenos sociales y se mueven en los terrenos de la que Luhmann denomina constitución de lo social y cuyo perímetro estructural no coincide con la reduccionista (en el decir del autor) Constitución política que fija selectivamente su identidad en el ámbito de las posibilidades sociales existentes y reina desde el universo de lo normativo y que condensa sólo un sistema parcial de sociedad. Para Luhmann, de entre las varias posibilidades existentes, caben dos clases de sistemas o subsistemas diferenciados. El primero de la sociedad y el segundo de la política que a través de la Constitución convierte las estructuras constitutivas de la sociedad en simples formas de expectativas de comportamientos normativos que se expresan en una relación de conformidad o disconformidad respecto del orden jurídico-constitucional. Esta noción se contrapone en términos no jerárquicos sino de interacción comunicativa, a un modelo sociológico de constitución que cumple la función de reformular para el sistema político las condiciones que hacen posible su compatibilidad social. Es así como la Constitución tiene por misión asegurar la compatibilidad, el orden y la ordenación de la funcionalidad del sistema a través de un procedimiento que legitima, la llamada legitination durch verfabren. 
La Constitución política se perfila como un intento de reducción de la complejidad que aspira a introducir orden en un mundo inabarcable y contingente y que, por ello, precisa mantener una compatibilidad social con el resto del sistema que le confiera su operatividad real. Se entiende que semejante planteamiento haya ejercido una tremenda fascinación sobre la mejor doctrina jurídica europea (el último Bobbio), del que se han contagiado nuestros mejores constitucionalistas, como se entiende también su utilidad para establecer las condiciones de compatibilidad ambiental y los resultados de funcionamiento operativo de una institución como la Corona. Pero no se trata de traer a colación las abstrusas y difícilmente inteligibles elucubraciones de Luhmann sobre las condiciones ambientales que hacen posible el cumplimiento de las funciones que la Constitución se autoimpone, sino procurar dar un paso a un lado y preguntarse si sus aportaciones sobre la diferente dinámica evolutiva de lo político-normativo y lo social no tienen algo que enseñar a la comprensión de nuestro propio proceso democrático y especialmente del momento de gestación de sus orígenes $\mathrm{Y}$ es que al afirmar la interacción de lo social con la Constitución política, Luhmann establece también un distingo crucial entre planificación y evolución, que separa la marcha organizada y artificial de la Constitución normativa de la evolución natural propia de la constitución social.

Frente a la planificación intencionada y racional que caracteriza a las constituciones (revolucionarias) modernas, Luhmann sitúa la evolución «ciega», no generada por un centro o vértice único (multicéfala o policéntrica), no inmersa en una relación de causalidad sino resultante de una elaboración procedente de fuerzas y opciones ocasionales muy diversas —y hasta contradictorias - que identifica a los procesos de la constitución social y no orientada a una meta predefinida de antemano. Estamos ante dos formas de entender el cambio que en ocasiones se proyectan de manera paralela y que pueden coincidir o no. En el momento revolucionario del siglo XviII que precedió a la consagración semántica del concepto político de Constitución (Stourzh), se dio esa coincidencia en la medida en que las adquisiciones de la evolución social fueron incorporadas a la norma constitucional que entonces se definía en su nuevo uso lingüístico. Se produjo de este modo una compenetración entre ambas que tuvo mucho de excepcional y que Luhmann ve como una reacción a la creciente diferenciación entre derecho y política que por entonces parecía imponerse y de cuya evitabilidad pro futuro parece dudar seriamente. Pero no hace falta ir más allá para entender que muchos de los acoplamientos estructurales que se terminan imponiendo en la vida colectiva merecen y en la mayoría de los casos exigen, ser tipificados como adquisiciones evolutivas que no responden a un origen causal ni predeterminado. Y en este sentido, hay que decir que nuestra Transición política participó mucho más de los rasgos de esta segunda forma de acoplamiento que de las que eventualmente le ofrecía el conocido — y temidoesquema del Poder Constituyente revolucionario que cuajó en el «abril de los capitanes» de 1974. 
Y basta echar una ojeada a los hechos que en España marcaron la adquisición de los hitos más decisivos de la Transición hacia la democracia, para atestiguar fehacientemente lo que entonces sucedió. Con la entronización del rey Juan Carlos y una vez demostrado con la desnortada experiencia del gobierno Arias que la continuidad política del régimen era ambientalmente inviable y que Fraga, tan intelectualmente atento de ordinario, estaba empíricamente equivocado porque el «bunker» carecía de la consistencia y del arraigo social suficiente como para evitar nada, se impuso la cordura. De manera que la necesidad de acoplar la institucionalidad franquista a la nueva atmósfera política que la sociedad empezaba a exigir de forma cada vez más impaciente, saliendo incluso a la calle, estuvo en la causa de la irrupción de acontecimientos tan señeros y tan transformadores de la organicidad existente como, el pacto con la oposición sobre el régimen electoral que bajo mano cuajó en el seminario académico celebrado por el CITEP en el hotel Eurobuilding de Madrid, en diciembre de 1976 y que mediatizó y estuvo en la clave de la redacción de la Ley para la Reforma política y del Decreto-Ley electoral de 1977; o como el acuerdo soterrado que llevó a la legalización del Partido comunista previo acatamiento de la Monarquía y que marcó las fronteras ideológicas de la democracia naciente; o como la preconstitucional restauración (restablecimiento jurídico) de la Generalitat de Cataluña que se tradujo en el pactado regreso del presidente Tarradellas del exilio, y que desembocaría en la paulatina extensión - y una vez más preconstitucional- del modelo autonómico a todo el territorio nacional.

Todos estos acontecimientos, salvo el último — que siguió muy pronto-, fueron previos a la reunión de las Cortes de julio de 1977 y obviamente, resultaron anteriores a la culminación de las labores de la ponencia constitucional. Y no hay duda de que de una forma policéntrica y no jerarquizada, desencadenaron una dinámica que la redacción de la Constitución continó y llenó de contenido técnico, pero no creó. Es decir, que la Constitución político-normativa fue más el resultado de un proceso evolutivo en el que finalmente se consagraron muchas de las adquisiciones que — como acredita el citado trabajo de Luis García San Miguel — ya habían ido madurando en la atmósfera social desde finales de los sesenta, que la consecuencia directa de un proceso de ruptura y de creación ex novo de la realidad que pusiera en uso social nuevos conceptos que la existencia colectiva desconocía y a los que debiera forzosamente adaptarse. Por eso, la categoría de Poder constituyente omnipotente y subjetivo uni-céntrico, no permite explicar satisfactoriamente la Transición española (también en este caso resulta ser un lecho de Procusto). En puridad no hubo revolución fundante porque la continuidad a través del procedimiento ocupó el lugar de la ruptura revolucionaria en la medida de que lo que se trataba de conseguir era que el proceso — se puede decir que natural — de trasferencia de lo que había en la sociedad a la vida política, no descarrilara, no saliera de las pautas instrumentales que legitimaban el tránsito político.

Ello quiere decir —e importa sobremanera dejarlo claro- que en España, primero se operó un colosal proceso de cambio real en los fondos sociales que pudo ser 
trasladado a la política a través del mecanismo electoral pactado (Ley para la reforma política) y que una vez muerto Franco tuvo su reflejo en las instituciones constitucionales. Por supuesto, el franquismo pereció irremisiblemente cuando con la muerte del dictador (la única institución petrificada del viejo sistema) el medioambiente social consiguió enseñorearse completamente de la política. El cambio real se impuso ciertamente en términos políticos, sólo que desde la continuidad procedimental con lo que existía. Fue así como lo que ya se había logrado socialmente y flotaba en el ambiente, forzó y determinó el cambio institucional. Eso lo comprendió muy bien un monarca que buscó en todo momento readaptar la institución que encarnaba a la nueva realidad social. Y ciertamente lo logró.

Y es que, conviene insistir en ello, fue en la vida social dónde, antes que en ningún otro sitio se produjo el cambio político en España. Fue en la sociedad dónde primero se ganó la batalla de la democracia, de manera que en 1975 el verdadero problema consistía en cómo trasladar a la política lo que la sociedad experimentaba y conocía ya incipientemente: una democracia postmoderna. La España que surgió de la Guerra Civil era en efecto una sociedad que había roto radicalmente con un pasado que resultó destruido a sangre y fuego en tres años de terrible contienda civil (de «cataclismo» como afirmara Nicolás Ramiro) y arrasado todavía más en una postguerra en la que la palabra clave para el régimen era «depuración» (etimológicamente limpiar o purificar). Un régimen que fue revolucionario en el sentido hobbesiano del término, que implica edificar de nuevo y desde nuevos cimientos la sociedad y el Estado. Todo se destruyó y reconstruyó de nuevo en la postguerra para conseguir que fuera puro, que no estuviera contaminado con los «umori» del pasado. Y la reconstrucción fue hecha a consciencia por un militar que se conocía de memoria a Clausewitz y que contaba con sobrada experiencia en hacer la guerra. Un general que se quedó con el poder político como botín de guerra y que obligó a los españoles a reconformarse vitalmente como una sociedad sin política, como un red de convivencia estructurada al único propósito de ganarse la vida, de progresar y de mejorar en su existencia cotidiana en paz y sin ninguna pretensión de obrar políticamente. Ambición de prosperar y temor a la guerra, eran el leitmotiv, los dos grandes afanes que resumían los «umori» de la sociedad que los españoles había construido en 1969, cuando una inteligencia tan preclara como la de Max Aub hizo su, en muchos sentidos, frustrante viaje de retorno a una España que ya no reconocía y del que saldría ese impresionante testimonio que fue La gallina Ciega ${ }^{19}$.

19 «En ningún momento tuve la sensación de formar parte de este nuevo país que ha usurpado su lugar al que estuvo aquí antes; no que le haya heredado. Hablo de hurto no de robo. Estos españoles de hoy se quedaron con lo que aquí había pero son otros. Entiéndaseme: claro que son otros por el tiempo, pero no sólo por él; es eso y algo más; lo noto por lo que me separa de su manera de hablar y encarase con la vida. No es el progreso, no es el turismo sino algo más profundo». Max Aub, La Gallina Ciega, 4 de noviembre 1969, pág. 596. Curiosamente Aub escribía el mismo año en que Luis San Miguel firmaba su trabajo citado. 
Pero no se trata de ir más allá en esta cuestión, solo de constatar, por un lado, que la política oficial de la España de 1975 estaba desacoplada (no era coetánea) de la sociedad que imperaba en la realidad interna. Y que por otro, y esto hace directamente a nuestra argumentación, de recordar que esa misma sociedad resultaba perfectamente contemporánea de la que con los años se había impuesto en la Europa democrática y en los Estados Unidos de América, donde se había originado el modelo de hombre al que aspirábamos. La diferencia era de cantidad no de cualidad. Lo que nos separaba eran las disponibilidades materiales, no los modos de sentir. Ambas tenían en común un modelo de vida en el que como advirtiera Constant, los disfrutes privados habían ocupado definitivamente el lugar de las preocupaciones e intereses públicos. El reto en el imaginario colectivo era consolidarlo evitando que un nuevo conflicto [in-]civil arrasara lo que tanto sufrimiento había costado reconstruir. El desafío pasaba por incrementar la prosperidad. El objetivo compartido de la sociedad española era socializar el Estado para adecuarlo a la realidad efectiva de las cosas, para acabar con la institucionalidad de una dictadura de carácter personal, que por su atipicidad respecto de los modelos imperantes en el resto de las naciones del entonces Mercado Común, obstaculizaba cualquier progreso social ligado a la integración europea. Un régimen que por su misma definición, evitaba que la sociedad continuara avanzando en la dirección que el dictador había señalado como única meta susceptible de resultar legítimamente invocada en la vida civil española. Y Franco y el franquismo resultaban ya disfuncionales porque impedían a una sociedad segura de su posición, tutelarse a sí misma en sus ambiciones de ascenso, movilidad y libertad social —que importaba tanto o más que la libertad política en sentido clásico ${ }^{20}$. Una sociedad que veía en Europa la solución que podía asegurarla en sus propias fuerzas, no podía ser compatible en términos sociales con el franquismo político. Por eso justamente Europa fue el gran referente de la transición y ha sido también el referente que ha movido la ambición social española durante estos últimos cincuenta años.

Dos son las enseñanzas que cumple recordar de todo este planteamiento. Primero, que la Constitución que resultó de aquél logro evolutivo incorporó mecanismos de apertura medioambiental como fuente comunicativa (adquisitiva se podría decir) de lo nuevo, que suscitarían una permanente tensión con las estructuras jurídica-normativas que procurarían ahormar los cambios sin conseguirlo en muchas ocasiones. En este sentido conviene insistir en que la propia forma de gestación de la Transición

${ }^{20}$ Las resistencias al cambio estaban más en el sector procedente de la oposición democrática que dudaba del deseo real del régimen de renunciar a serlo, que de las fronteras internas de un franquismo que en su mayoría se contentaba con no ser inquietado en su pacifico disfrute social. Un temor que la vecina revolución portuguesa había refrescado. El obstáculo principal fue pues, convencer a la oposición de que no se trataba de atraerla a una jaula que sirviera para diera la apariencia de legitimidad democrática, sino de jugar las reglas de la democracia que hacía posible una efectiva alternancia en el poder. 
a la democracia determina que nuestra Constitución no conozca un momento fundacional al que retornar normativamente sostenido. La Constitución española de 1978 es un hito clave fundamental sí, pero a fin de cuentas, un hito más en una cadena que arranca de muy atrás, de la revolución política y social que se originó en la Guerra Civil y con la reconstrucción franquista. Y supone un punto en la evolución de un proceso de adaptación a una realidad de la que es parte integrante y activa, y que también precisan asegurar su compatibilidad respecto del entorno cambiando con el medioambiente (Luhmann). Y es que en la Transición política española no existe un principio al que volver como sucede allí dónde la experiencia revolucionaria marca el nacimiento de un mundo.

Nuestra Constitución aparece sencillamente como un eslabón en una cadena que tuvo por misión iniciar un movimiento nuevo que no niega el pasado sino que lo incorpora deglutiéndolo y haciéndolo propio. Lo que significa que no puede servir de fundamento legitimador de otra cosa que no sea el puro procedimiento que hace posible su existir en movimiento. Algo que tira por tierra las expectativas de aquellos autores que pretendían situar en la Constitución la legitimidad que a la magistratura monárquica le niegan quienes defienden la Republica desde los argumentos de su incoherencia espiritual-sociológica con la igualdad o desde las razones de su incompatibilidad técnico-jurídica o político-lógico con la democracia. Y es que la única explicación susceptible de ser admitida en nuestro entendimiento posmoderno de la política capaz de legitimar la monarquía de manera inapelable, es su funcionalidad democrática (más efectiva y superior que la de un presidente de la República) y eso no tiene que ver sólo con lo que obre recogido en la letra de la Constitución, sino en su utilidad funcional concreta. Y es que la vieja distinción medieval legitimidad de origen y de ejercicio ha quedado tan obsoleta en el mundo postmoderno como la tradicional contraposición ontología/fenomenología, o el filosófico distingo entre ser y existir.

La Constitución española de 1978, coherente con las nuevas ideas que empezaba a impregnar la época, tendió hacia una cierta desideologización que atenuó la fuerza transformadora y dirigente que caracterizaba a las Constituciones de postguerra, que iniciaron su andadura con la italiana de 1947 y la acabaron en la portuguesa de 1977, y sin dejar de proclamar rotundamente su fuerza vinculante procuró presentarse al mismo tiempo como un proyecto normativo abierto a la sociedad y a sus cambios, tanto interiores como del medioambiente exterior. No hace al caso entrar aquí en profundidades que se evidencian en datos como el hecho de la ausencia en el Título $\mathrm{X}$ de nuestra Constitución de cláusulas pétreas que condensasen y resumieran expresivamente la ideología del sistema, detectado por Jiménez Campo. De lo que se trata únicamente es de reparar en qué y a diferencia de las Constituciones revolucionarias de postguerra, el texto español de 1978 no expresa tanto un proyecto de transformación social como encarna en sí mismo el deseo de consolidar un Estado Social y Democrático de Derecho cuyo significado e implicaciones nadie cuestionaba ya en el arco de los partidos constitucionales, y a 
la postre a intentar integrar en un mismo plano normatividad y apertura. Apertura que se hace particularmente evidente en la praxis del Estado de las Autonomías y en el propio mecanismo previsto para la incorporación a la Unión Europea o en el artículo 10.1 CE relativo a derechos. No en vano las tesis de Peter Häberle sobre la Constitución abierta, han tenido entre la literatura constitucional española una inusitada acogida que supera con creces la dispensada por cualquier otra doctrina europea.

En segundo lugar hay que decir que independientemente de cual fuera el deseo de Franco respecto del futuro, no parece demasiado admisible en términos de lógica explicativa, ver en el rey un elemento de continuidad del franquismo que el mismo monarca contribuyó claramente a superar. Muy posiblemente porque le iba en juego la continuidad de la institución que él encarnaba, pero la política democrática no desconoce los intereses sino que se nutre de ellos objetivándolos y generalizándolos. No es correcto conceptualmente hablando, enarbolar la bandera de la República afirmando que la dictadura pervivió en el monarca en forma de régimen político, tratando de resucitar artificialmente la vieja querella binaria Monarquía/Republica en un contexto sociológicamente muy diferente y en el que la monarquía es todo menos un régimen político. Y si se hace así, y si alguien pretende recurrir a este argumento en el debate de la política actual, posiblemente sea porque carece de categorías intelectuales y de elementos suficientes para entender lo que ahora está ocurriendo en la vida social y política española, en la que, como sucede en el resto de Europa, aquello que — a resultas de la mal llamada crisis financiera y de la mundialización - se ha venido abajo es un modelo democrático que asentaba sus reales en la renuncia a los deberes públicos en favor de los goces privados. Un modelo en el que lo importante era la plenitud individual y no la existencia común y colectiva. En el que lo que tocamos ha sido superado por lo que imaginamos. En el nuestras ambiciones se identifican con lo que Hegel llamaba necesidad, más que con la libertad propiamente dicha. Pero igualmente esta cuestión escapa a nuestra investigación, que se limita a constatar que la monarquía que algunos sectores tachan rotundamente de franquista y pretenden sustituir por una magistratura electiva, data — como por lo demás el propio sistema electoral- de la Transición y por consiguiente es obra de una sociedad que habiendo repudiado medioambientalmente el franquismo, también quería revocarlo políticamente.

No fue este mismo papel el que le tocó desempeñar al anterior monarca a lo largo de todo su reinado que discurrió entre 1975 y 2014 . Para resumirlo puede decirse que en casi cuarenta años se dieron dos tipos de situaciones separadas por una quiebra el 23 de febrero de 1981, que operó como barrera en los comportamientos reales. Inicialmente el rey ejerció plenamente su poder en favor de la democracia contribuyendo a acoplar evolutivamente la institucionalidad franquista a un medioambiente que reclamaba el dominio social de la política. Luego y toda vez que para defender el logro de la democracia recién adquirida, el monarca hubo de invocar 
un mando que constitucionalmente no le competía pero que contó con la plausibilidad social, su figura se desvaneció y pasó a operar como un instituto políticamente irrelevante sólo activo socialmente, aunque siempre comunicativamente alerta. Todo lo cual, cuando la sociedad se puso nuevamente en marcha reclamando una democracia veraz, le llevó a abdicar renunciando a una magistratura que no gozaba ya de credibilidad entre la sociedad. Sólo esto salvó a la monarquía, su condición de órgano al que a fuerza de renovarse personalmente, la institucionalidad puede llegar a soportar situaciones ambientales muy diferentes que, por su parte, también dan lugar a comportamientos y desarrollos funcionales muy diferentes por las personas que ostentan la corona.

\section{LA MONARQUÍA PARLAMENTARIA ESPAÑOLA EN SU SIGNIFICACIÓN CONCRETA}

\section{A. Monarquía y modernidad política: legitimidad e identidad de la Monarquía}

Uno de los supuestos pre-comprensivos que más urge clarificar cuando se aspira a conceptualizar la Monarquía, consiste en explicar que su existencia intelectual se circunscribe estrictamente a un determinado Tiempo histórico que tal y como afirma John Pocock, no representa otra cosa que la expresión auto-consciente de un espacio público compartido. Frente a las tesis que asocian la figura del monarca con cualesquier organización coronada que en el pasado haya sido, de suerte que la simple concurrencia de un Príncipe hace posible reconocer la presencia de una configuración estatal monárquica, hay que afirmar que la monarquía que aquí se pretende investigar es privativa de la cultura moderna y con ella, de la irrupción de la legitimidad como categoría política. Una categorización que, se quiera o no, resiste sustancialmente incontestada hasta nuestros días, lo que a mayores, nos permite dejar al margen de nuestro estudio toda consideración sobre las actuales monarquías de raíz religiosa o tribal ${ }^{21}$.

En efecto, es cierto que el pasado conoce numerosas experiencias de gobierno personal a las que se les atribuye la denominación de monarquías. Sin embargo, a lo que aquí nos estamos refiriendo es única y exclusivamente a aquella estructura monárquica de poder que emerge en el contexto del Estado y de la modernidad política. Frente al mundo de los Antiguos, el Estado significa el triunfo de una concepción de la vida en la que los hombres crean desde abajo y por sí mismos las

${ }^{21}$ Cualquier observador imparcial constata que las Monarquías de los países musulmanes tienen otros fundamentos que resultan por completo extraños a nuestro mundo y a nuestra lógica y que se corresponden con fundamentos de tipo religioso o tribal. Tal es el caso del rey de Marruecos, sin ir más lejos, que a su condición de Monarquía religiosa suma la circunstancia de que allí hasta hace muy poco el rey recibía la sumisión tradicional clientelar en la ceremonia de vasallaje. Los ejemplos podrían multiplicarse hasta lo infinito. 
realidades de la política. Incluso el Estado absoluto es la obra de un hombre, el Príncipe. Estamos ante lo que Walter Ullmann llama concepciones ascendentes del poder y la política, en las que corresponde a la base social el impulso que supondrá la creación del Estado. Y el dato resulta clave para lo que aquí se pretende, porque en lo sucesivo será la sociedad la que de vida a la política y la que vertebre al poder y no a la inversa. Las monarquías que surgen en este proceso ofrecen unas características claramente diferenciadas de las precedentes feudales que se resumen en la vinculación a una cultura política crecientemente secularizada — aunque durante mucho tiempo se mantenga todavía de manera ciertamente intencional una enorme confusión entre monarca y fe religiosa-, la institucionalización orgánica de la persona que ostenta la Corona de forma jurídicamente complicada y en la práctica escasamente diferenciada, y una confianza en que la figura del monarca vitalicio asuma el papel de punto de estabilización frente a los avatares que empiezan a emerger con la aparición de lo nuevo (modernidad). Y ello se hará realidad tanto en las Monarquías que efectuarán internamente el tránsito desde la feudalidad hacia la modernidad (Francia), como en aquellas Republicas que evolucionarán desde una ciudadanía cívica más o menos consolidada, hasta terminar desembocando en el Principado, aunque sin duda, institucionalmente será mucho más evidente en estas últimas en razón a que en ellas la discontinuidad que supondrá la irrupción del monarca resultará meridianamente clara, mientras que en las primeras se operará un tránsito evolutivo necesariamente enmascarado que fungirá de continuidad histórica.

\section{El rey como institución vitalicia y hereditaria}

Pero volviendo a nuestra hipótesis referida al nacimiento electivo de las monarquías modernas, hay que señalar que al contrario de lo sucedido en Francia, en algunas ciudades-Estado italianas y en los Países Bajos holandeses, el debate discurrió por derroteros más claros y rupturistas, en la medida en que lo que allí se confrontó intelectualmente fueron las ventajas que deparaba la institucionalización monárquica contra las virtudes de la participación republicana. Frente a un tránsito hacia el absolutismo que nace de la transformación del monarca feudal en Príncipe moderno, la crítica republicana opondrá unas comunidades de base democrática que verán en el magistrado a vida un valladar capaz de enfrentar la inestabilidad que la Fortuna traerá consigo.

Como ha explicado Felix Gilbert la aparición de la figura del Gonfaloniero a vida, en la postrera etapa de la República de Florencia, tiene lugar en un contexto de evolución hacía la monarquía en el que se afirmará un nuevo modelo de magistratura que incorporará tres cualidades hasta entonces incompatibles con la concepción republicana de la política: la confusión entre persona y oficio, el carácter vitalicio del cargo/magistratura y la preocupación por la estabilidad de la Ciudad frente a la dinámica rotatoria de las instituciones republicanas. La rotación en los 
cargos era un principio inherente a la democracia republicana en la que se exigía la completa implicación de la ciudadanía en la construcción de los acuerdos colectivos. Esa rotación de los cargos, sagrada en la República, encontraba su principal inconveniente en la fugacidad del componente humano de unas instituciones que al resultar constantemente renovadas terminaban perdiendo la continuidad de sus políticas en momentos en que los problemas exteriores amenazaban con destruir la vida cívica. Y algo muy similar vino a suceder en Holanda dónde, en medio de guerras exteriores, a partir del siglo XVII la figura del Estatúder se transmuta en una magistratura monárquica.

A la postre, el argumento de la estabilidad se convertirá en la gran baza de fondo que terminará inclinando la balanza en favor de la implantación de la monarquía y en detrimento de la república. Un argumento que además, examinado desde una perspectiva analítica-funcional, nos permite atisbar una distinción clave que contrapone los dos supuestos que contribuyen a la categorización de la institución monárquica moderna y que de sólito se confunden porque casi siempre se presentan juntos: la herencia y el carácter vitalicio del oficio.

E interesa detenerse con algún detalle en examinar esta cuestión, porque precisamente de aquí derivan tanto el carácter vitalicio de la magistratura real, como la propia razón que funcionalmente justifica su papel institucional vinculado a la permanencia y a la continuidad de la política. Nos estamos refiriendo a la idea de estabilidad que encarna el Estado. En relación a lo primero, es cierto que habitualmente se afirma que la monarquía se corresponde lógicamente con la institucionalización de la herencia y que en definitiva, se identifica con un principio dinástico que menosprecia la igualdad y niega directamente las más arraigadas convicciones que dan vida a la noción de ciudadanía: la exclusión por nacimiento de la posibilidad de desempeñar la primera magistratura de la nación. No viene al caso reiterar lo que ya se dijo al respecto antes, ni tampoco traer nuevamente a colación aquí la ofensa que la condición hereditaria comporta para todos aquellos a los que excluye, la inmensa mayoría de la población, prácticamente toda cuando no existe una aristocracia hereditaria. Sin olvidar la importancia que este factor tiene entre nosotros en el momento de enjuiciar la fundamentación de la monarquía y las razones que la abocan a procurarse de manera angustiosa una aceptación credencial por la sociedad que no tiene parangón en ninguna otra institución constitucional y que una presidencia de la República electa y salida de las urnas no precisa ni por asomo. Lo cierto es que $-\mathrm{y}$ hay que decirlo con tranquilidad - la monarquía y el principio dinástico no son en absoluto la misma cosa. Para repetirlo con otras palabras, la herencia no es esencial a la monarquía, entendiendo por esencial aquél requisito que al ser consustancial con la identidad de una institución no puede desaparecer nunca, esto es, cuya pérdida generaría una desnaturalización de la magistratura que una vez vacía de la sustancia que le da el ser, se convertiría en una suerte de carcasa formal irreconocible y capaz de albergar cualquier contenido menos el que la identifica y singulariza como tal. Lo que no quiere decir que la herencia no sea un 
elemento habitual de la Monarquía y que también no se produzca muy frecuentemente una completa identificación práctica entre una y otra; hasta incluso hacer perder la memoria de su diferente esencialidad teórica ${ }^{22}$. Conviene recordar al respecto que, pese a que lo parezca, cuando hablamos de un rey hereditario y de por vida, no estamos, en presencia de un solo e idéntico supuesto que quepa en una fórmula indisociable, porque no es lo mismo la perpetuidad en el oficio que su procedimiento de transmisión y porque mientras el segundo es sustancial, el primero sin dejar de ser fundamental, tiene algo de circunstancial y accesorio, como lo demuestra el hecho de la existencia de monarquías electas, una figura que subsiste todavía en nuestros días en la más vieja monarquía del mundo, la Iglesia Romana.

Y no se trata de especulaciones de un teórico, sino constataciones nacidas del estudio del artículo 57. 3 de la Constitución. Una norma que por mucho que se presente como disposición de carácter excepcional, ocupa un lugar en la manera de designar al rey que nada tiene que ver con la idea que informa el principio dinástico. Lo dicho comporta una consecuencias importantes en la medida en que remarca la enorme importancia que el factor vitalicio cobra para entender la dinámica en que se hallan insertas en general las modernas monarquías parlamentarias y en particular la única que verdaderamente nos interesa, la española. A lo que, además, hay que sumar desde el ámbito de la reflexión constitucional, la circunstancia de que la vinculación entre Monarquía y familia se evidencia como un supuesto bastante más contingente de lo que tradicionalmente pensaba la, en este concreto tema, hace cuarenta años anquilosada doctrina del derecho constitucional español, como muy bien supo intuir en su día en una pionera y premonitoria tesis doctoral, la profesora Yolanda Gómez ${ }^{23}$.

En resumidas cuentas y sin ánimo de menospreciar la transcendencia del principio hereditario, a lo que modestamente aspira este trabajo, es a llamar la atención sobre el otro gran elemento (doctrinalmente olvidado) que construye la médula de la monarquía, la vitalidad de la magistratura, su irrevocabilidad, en el propósito de poder examinar su aportación a la funcionalidad de la vida política de una democracia constitucional como la española.

22 Así, por ejemplo, señala Enrique Belda que la principal incompatibilidad democrática de la Corona deriva fundamentalmente de su nacimiento. Enrique Belda «Reforma constitucional y sucesión», en Rubio Llorente, F., Álvarez Junco, J., El informe del Consejo de Estado sobre la Reforma Constitucional, cit., pág. 280. Véase Tomás Villarroya, J. «Artículo 57: Sucesión a la Corona», en Alzaga, O., Comentarios a la Constitución Española de 1978, Tomo V Madrid 1997. Torres del Moral, A., El Príncipe de Asturias. Su estatuto jurídico, Madrid, 1997, pág 72.

${ }^{23}$ El derecho constitucional relativo al matrimonio y a la familia arts. 32 y 39 de la Constitución española.

UNED 1987. Publicada luego en el libro Gómez, Y., Familia y matrimonio en la Constitución española de 1978. Madrid, Congreso de los Diputados, 1990. La profesora Gómez ha coordinado también la obra XXV años de monarquía parlamentaria, Sanz y Torres, Madrid, 2006. 
2. El rey como expresión de un Estado que monopoliza lo político

Es Hexter quien en su trabajo sobre Maquiavelo nos enseña que la expresión que más veces aparece repetida en el Príncipe es «mantenere lo Stato». Más allá de lo acertado de la afirmación lo cierto es que la obra del florentino es claramente tributaria de las preocupaciones expresadas en su época. No hace al caso entrar en demasiadas consideraciones al respecto, pero lo que sí importa retener es que una de las grandes inquietudes de la época, sino la más acuciante, fue estabilizar, dar continuidad a la Política, «mantenere lo Stato». «Mantenere lo Stato» significa varias cosas a la vez. Por un lado, implicaba defender el orden político frente a la contingencia absurda, irracional, ilegítima y destructiva que encarna la Fortuna. Defender lo que hoy se conoce como gobernabilidad de la política, evitando que el quehacer cotidiano convierta la acción pública en una colección incoherente de respuestas a lo que cada día buenamente surge. Pero por otro «mantenere lo Stato» también significaba la prevalencia del interés de todos que Florencia simbólicamente residencia en el commune, sobre el particular interés de las distintas partes o de los fragmentos que conjuntamente integran la República. Se trataba de algo así como aquella categoría que los cultivadores del derecho administrativo llaman el interés público que, por ejemplo, a través de instrumentos como la expropiación, permite privar a los sujetos particulares del disfrute de sus bienes y derechos para un fin de utilidad pública.

Un rey en la cúspide de la política estabilizaba el poder y ponía coto a la Fortuna, pero lo más importante era que allí donde esta situación se llegó a producir, el rey absoluto significa a la vez, interés público y poder de supremacía. Una idea de publicidad que ofrecía pues dos caras, la de poder exorbitante y la de representar a todos, y que nada tiene que ver con el derecho romano porque es compatible con la legitimidad que emana de una sociedad que Roma no llegó a conocer nunca. Es por eso por lo que allí dónde el absolutismo o sus categorías no encontraron asiento, no llegó a arraigar el Estado entendido como autoridad pública, de manera que la publicidad no consiguió ser una autoridad participada por todos y a la que desde la irrupción de la opinión pública, estudiada por Habermas, todos tenía tanto obligación de acatar como derecho a conocer. Sin embargo donde hay Estado, lo público es de todos porque todos deben obedecerlo y porque todos pueden acceder a su conocimiento sin que ninguna traba posible pueda oponérseles. No hacen al caso mayores disquisiciones al respecto, ya que lo único que, en verdad conviene dejar meridianamente claro a nuestros efectos, es que el rey en cuanto «jefe del Estado» [y] «símbolo de su unidad y permanencia» es un órgano público como bien dice Fernando Rey, que opera , añadimos nosotros, sujeto a la voluntad popular expresada por otros órganos constitucionales —y eso significa el refrendo- pero también es una persona sujeta en la totalidad de su existir vital a la condición de agente público y por consiguiente al que le incumbe la terrible carga de no conocer intimidad privada, por mucho que alguien diga lo contrario. Es la carga de la monarquía que no siempre resulta posible de sobrellevar humanamente, y también una cierta compensación a la ofensa que para el común de 
los mortales, supone el hecho de su exclusión de los cargos públicos que señala el artículo 23,1 CE.

Pero más allá de todo ello y desde una perspectiva de organización constitucional lo fundamental es que el rey es la suprema encarnación del Estado, y que esta circunstancia comporta las consecuencias que hemos señalado cuando planteábamos el papel de los «órganos constitucionales de soberanía o de dirección Estatal» cuya función consiste en expresar o contribuir a que otros expresen la voluntad colectiva que recoge el sentir político colectivo. A tal fin el papel del rey es doble, por un lado debe contribuirá a articular consenso constitucional y por otro, está llamado a propiciar, apoyar y favorecer o potenciar el máximo rendimiento — en términos de Kalterfleiter «Arbeittsfäbigkeit»— de las diferentes instituciones que integran el sistema democrático. Al respecto de ambas funciones, y como jefe del Estado necesita de cierto apoyo de todas las agrupaciones políticas. Consiste en obrar con imparcialidad y neutralidad en el sentido de que todos los grupos entienden que tal facultad e influencia no presupone imposición de ningún tipo de exigencias a los grupos políticos, sino únicamente actuar de cara al encauzamiento del sistema político. Y para ello requiere, por un lado, del reconocimiento de la neutralidad de su obrar y de otro, de la credibilidad del entramado social que ve en la sinceridad de su actuar la mejor garantía del interés público. Uno y otro son diferentes pero cuando funciona correctamente convergen en el mismo sentido.

\section{Los deberes del rey neutral en una Constitución democrática}

Como entreviera con lucidez Benjamín Constant, la Democracia de los Modernos se caracterizara por incorporar como dimensión irrenunciable de su concepto de política la naturaleza pluralista de la sociedad. Una sociedad democrática moderna está forjada en la diversidad humana y reconoce como realidad permanente el hecho de vivir en la diferencia. La diferencia es estructural y no una circunstancia ocasional. Por eso el pluralismo resulta tan importante para la democracia moderna como lo es el mismo supuesto electivo. Se participa en política a través de las elecciones, concurriendo como candidato o eligiendo la opción más conveniente, pero tras las elecciones la diferencia y la estructura de pluralidad social que la sostiene, permanece y continuará subsistiendo siempre. La política democrática consiste en encontrar el acuerdo sin renunciar por ello a mantener la diferencia. El acuerdo es puntual y coyuntural, la diferencia y la pluralidad son estructurales porque expresan lícitamente la propia variedad humana. En política democrática el conflicto es inevitable, aunque, como señalara Herman Heller, se resuelve siempre finalmente en el acuerdo. Un acuerdo que no borra la diferencia pero que permite salvarla temporal y puntualmente. El riesgo está en la capacidad de las instituciones para soportar la tensión que genera llegar a ese acuerdo y máxime cuando esa tensión es continúa, y se repite permanentemente como coste inevitable de la democracia. Justamente aquí empieza el papel del rey en democracia como magistratura llama- 
da a procurar impedir, desde la más estricta neutralidad política, que el conflicto se desborde y que las instituciones estallen asegurando la continuidad del sistema. Es este el rol que también lleva implícito muy sutilmente la exigencia de atestiguar que el acuerdo no concluye en una simulación hueca. Es decir, que no se configure como una apariencia tras la cual subsiste en realidad un engaño político destinado a confundir a la ciudadanía durante un cierto lapsus temporal. Lo contrario sería dar por verosímil lo que sólo es mera falacia, condicionando la estabilidad de la magistratura monárquica sobre la que a no tardar recaerían las consecuencias de haber dado cobertura al engaño, comprometiendo y haciendo impensable su propia continuidad. No es lícito engañar al pueblo - clamaba Condorcet - entre otras razones porque la impostura destruye la credibilidad y arrastra a las instituciones hacia una muerte segura en el tiempo. Tal es la única posibilidad de justificación de un rey en una democracia pluralista. Una justificación que además, para ser plausible, requiere que la sinceridad de sus actos se vea reconocida por la sociedad. Esto es, que su comportamiento subjetivo, de una parte, resulte conforme al contenido material de su tarea y, de otra, que la credibilidad que le confiere semejante conducta le depare la aquiescencia colectiva. Un cometido muy laborioso de realizar y que corresponde desempeñar a una persona que funge como institución, y cuya complejidad se acrecienta si se cae en la cuenta de que de sólito las instituciones despersonalizan los comportamientos y hacen que resulten abstractos y objetivos, previsibles y hasta rutinarios, mientras las personas son siempre subjetivas e incorporan la propia dimensión humana en su acción pública.

Es precisamente esa dimensión humana la que forja la singularidad de la función que al rey atribuye la Constitución y que de algún modo enlaza con el viejo debate sobre si es a los hombres o las instituciones a quienes cumple garantizar el correcto funcionamiento de la vida política. En el fondo, se trata de determinar si debe prevalecer la naturaleza humana o las creaciones artificiales de la cultura política bajo la forma de instituciones.

El rey poder neutral, tiene que hacer «política constitucional» al menos de dos modos. Uno finalista, propiciando y favoreciendo la consecución del consenso, y otro que se explica desde su tramitación, debe hacerlo en la forma preestablecida por la Constitución y las leyes, es decir, trasladando escrupulosamente sobre los partidos todas las cuestiones que tengan un tinte político determinado (por eso el refrendo del art. 56.3 y 64.1), pero velando porque se obtenga un resultado que, en la medida en que se encuentre más consensuado, será más objetivo, expresará mejor el parecer común, habrá fundamentado más y mejor la resolución política en el querer de todos.

En este sentido, parece que el rey no está neutralizado para hacer política constitucional, sino que debe ser neutral para llegar a hacerla. Y su política constitucional consistiría en todos aquellos actos, comportamientos o llámense como se quiera, intervenciones que contribuyan a reafirmar la Constitución y su espíritu (art. 62 y 63 y demás preceptos de CE.) Pero ¿aquí se acaba todo? O lo neutro de la instancia es 
justamente, el título que permite pensar en su aptitud para ejercer otra función también política, hasta más política que la anterior.

En rigor, todos los poderes están obligados a cumplir la Constitución y hacerla cumplir, lo que les obliga no sólo a comportarse ellos mismos en términos constitucionales, sino a imposibilitar que otros lo hagan y en algún sentido hasta a denunciarlo. ¿Pueden ser las instituciones constitucionales indiferentes ante un hipotético incumplimiento democrático que simplemente desconozca la Constitución? ¿Un órgano constitucional debe mirar a otro lado cuando sabe o tiene obligación de saber, que la Constitución no es acatada? ¿No es acaso deber irrenunciable de cualquier instancia constitucional respetar el contenido material de las normas que la integran o basta limitarse a cumplir las formas circunscribiéndose a las apariencias? ¿Es función del Rey mantener una mera apariencia cuando se incumple materialmente la Constitución, o cuando se burlan formalmente sus principios, o cuando se ignoran silenciosamente los deberes que las normas imponen o se deprecian socarronamente sus plazos? ¿Es o no cómplice la indiferencia cuando se trata del funcionamiento normal y legítimo de la democracia? ¿Es acaso el Rey la única magistratura constitucional que está exenta de un deber in vigilando que se extiende a todos los demás poderes? Si la respuesta fuera afirmativa, habría que concluir que la neutralidad política del monarca es en realidad una neutralización que le otorga una suerte de venia constitucional para permanecer, ciego, sordo y mudo ante lo que pueda pasar, independientemente de que se encuentre ante un simulacro que pueda llegar a implicar la aniquilación no ya de la monarquía, sino de la Constitución y de su misma fuente originaria, la propia democracia. Entramos en un terreno sutil y enormemente resbaladizo, que también es peculiar de la política. El de la diligencia, del deber inexcusable, de las presunciones tácitas o negativas, de la culpa in vigilando, de las omisiones... que es algo que tiene que ver con eso que se llama patriotismo o lealtad Constitucional. Patriotismo y lealtad que leídas en negativo suponen la interdicción de fingir o encubrir, de tolerar o no mirar... que también son infracciones porque lo que importa es el contenido democrático de las acciones — su lealtad e integridad de fondo hacia la Constitución y no sólo su envoltura constitucional.

\section{ESTRUCTURA Y FUNCIONALIDAD DEMOCRÁTICA DE LA MONARQUÍA}

De lo anteriormente expuesto se colige fácilmente que el Rey es un órgano constitucional de dirección estatal, emanado y definido directamente por la Constitución que comparte con los restantes órganos que tienen atribuida la función de indirizzo político, la tarea de caracterizar la forma de gobierno constitucionalmente establecida. Ello supone por imperativo constitucional, que no obstante su condición formal de jefe del Estado mantiene con los demás órganos superiores relaciones 
de in-ordinación paritarias, que los sitúan materialmente en una posición equitativa y de no subordinación mutua, marcada por el doble principio de interdependencia y control ${ }^{24}$.

Además, su especificidad concreta viene establecida por cuatro rasgos que resumen su forma de ser. En primer lugar, se trata de una magistratura a la que la figura del rey corporeiza física y humanamente y cuya existencia institucional sobrepasa la de la persona de su titular. Segundo, representa en sí mismo la unidad del Estado y como tal, es formalmente su órgano supremo, es por así decirlo el Estado en persona. Tercero, su identidad viene marcada por la condición vitalicia de su titular, lo que asegura su independencia y le permite marcar los tiempos de los otros órganos. Cuarto, la neutralidad marca su destino en una sociedad fundada en la pluralidad y necesitada de que una instancia suprapartidista articule el consenso constitucional y propicie la buena marcha del juego institucional ayudando a lograr dicho consenso y, sobre todo, procurando e impulsando en todo momento la veracidad de la política, de manera que contribuya a impedir que la Constitución degenere en un simulacro.

\section{A. La abdicación como mecanismo de responsabilidad extraordinaria y el estatus constitucional del rey}

Es muy posible que doctrinalmente no se haya reparado todavía lo suficiente acerca del sentido tan profundo y determinante que la abdicación adquiere para la definición de la Monarquía parlamentaria como institución democrática ${ }^{25}$. Más allá de las especificas condiciones que el muy confuso art. 57.5 CE impone para admitir la renuncia del monarca a la Corona, la abdicación es en sí misma, un acto tremendamente significativo que incorpora supuestos procedentes de las dos lógicas que confluyen en la magistratura real ${ }^{26}$. De una parte, constituye una

${ }^{24}$ Sobre esta cuestión, vid. las obras colectivas: Torres del Moral, A. (Dir.), Monarquía y Constitución, Madrid, 2001. Rollnert Liern, G. (coord.), Las monarquías europeas en el siglo XXI, 2007. VV.AA., La Monarquía Parlamentaria (Título II de la Constitución), Congreso de los Diputados, Madrid, 2001.

25 Sobre la abdicación puede consultarse mi trabajo «El rey neutral: la plausibilidad de una lectura democrática del artículo 56.1 de la constitución», en Teoría y realidad constitucional, N. ${ }^{\circ}$ 34, 2014, págs. 295-318. Vid. también Férnandez-Fontecha, M. y Pérez de Armiñán, A., La Monarquía y la Constitución. Madrid 1987 págs. 220 y ss; Belda, E., «Reforma constitucional y sucesión», op. cit., pág. 285.

${ }^{26}$ La abdicación es una decisión unilateral del monarca que actúa al respecto con absoluta libertad. En el fondo, es el único resto que queda en sus manos de soberanía, si es que el término puede ser utilizado sin generar equívocos. El rey que como rey ostenta un poder vitalicio, renuncia a su intemporalidad por su propia voluntad. Se trata de una decisión clave que está excluida del refrendo, el rey abdica bajo su absoluta responsabilidad y no cabe exigir cuentas a nadie de su acción como sucede cuando media el refrendo. El núcleo de la decisión corresponde al rey y la ley de Cortes es solo un control externo para asegurar que se quiso libremente. La necesidad de refrendo es señalada en sentido contrario por Marc Carrillo que la deriva del sometimiento genérico del monarca a la Constitución. Véase «Debatiendo la Sucesión a la Corona», Economía. Revista en Cultura de la legalidad N. 7 , Septiembre 2014-Febrero 2015. 
manifestación de voluntad (soberana) por la que se pone fin al desempeño de una función vitalicia. Es el rey quien libremente y sin necesidad de refrendo (por su único deseo) decide no seguir desempeñando la magistratura que ocupaba, lo que internamente comporta una renuncia unilateral y libérrima a la duración ilimitada a la estabilidad de por vida en el cargo, que es el elemento que confiere a la institución la independencia que caracteriza su obrar dentro del marco constitucional. De otra, la abdicación, cuando no viene motivada por razones relacionadas con la decadencia física o con la necesidad de anticipar una imposibilidad psíquica o de otro tipo que aquejen a su titular, implica perfectamente una asunción de responsabilidad por parte de un monarca que ha perdido su credibilidad y que tiene plena conciencia de lo que ello puede comportar, una eventual destrucción de la Constitución.

$\mathrm{Y}$ es que a este efecto, si bien es cierto que el mecanismo del refrendo determina que la responsabilidad ordinaria que deriva de las funciones constitucionales de la Corona la asuman quienes sitúan su firma debajo de la del rey ${ }^{27}$, no lo es menos que la responsabilidad sobre la suma íntegra de sus comportamientos y la manera de ejercer el cometido fundamental de la institución, recae exclusivamente sobre el propio monarca y su trayectoria. Un cometido que — como ya se vio- consiste en operar con neutralidad para que en el proceso político de formación de los consensos todo se realice materialmente conforme a la Constitución. Y esa tarea se convierte en extraordinariamente ardua y lábil cuando no se cuenta con otras atribuciones que una continua apelación a la norma y los dones que acompañan al hombre que la desempeña. El gran secreto para cumplir con ella es mantenerse siempre en consonancia con la Constitución y con la lectura que de sus preceptos efectúa la inmensa mayoría social. Es el sentir social quien marca hasta donde se puede llegar con la norma, y es también el sentir social quien formula el juicio de sinceridad sobre la actuación del monarca en todas y cada una de sus intervenciones. Cuando la persona del monarca recibe un veredicto desfavorable que compromete su credibilidad, la consecuencia afecta a la institución que pierde una aceptación funcional que precisa ser revalidada día a día, acto a acto y comportamiento a comportamiento. Un monarca que ha perdido su credibilidad no tiene otro remedio, si aspira a salvar la permanencia de la institución, que asumir su responsabilidad y renunciar. Es así como la abdicación viene a operar, a la vez, como un mecanismo que depura la responsabilidad individual del monarca y como una válvula de escape que posi-

27 Sobre la institución del refrendo, vid. González Trevijano, P., El refrendo, Madrid, 1998. López Guerra, L., «Las funciones del rey y la institución del refrendo», en Torres del Moral, A. (dir.), Monarquía y Constitución, Madrid, 2001, págs. 389-402. Porras Ramírez, J.M., «El principio de irresponsabilidad regia y el instituto del refrendo: Apuntes para un estudio en claves histórica y jurídico positiva», en Torres del Moral, A. (dir.), Monarquía y Constitución, Madrid, 2001, págs. 373-388. Herrero de Miñón, M., «Artículo 64. Refrendo de los actos reales», en Alzaga, O., Comentarios a la Constitución Española de 1978, Tomo V, Madrid, 2006. 
bilitando la sustitución personal, da continuidad y estabilidad de futuro a una magistratura que simultáneamente resulta ser una persona ${ }^{28}$.

B. Los actos del monarca en relación con los otros órganos constitucionales. El artículo 99 de la Constitución

La Constitución Española diseña la figura del monarca como un órgano unipersonal atribuido a un hombre. El rey es una persona física que además de jefe del Estado y titular de una serie de cometidos y obligaciones constitucionalmente tasados y precisados, tiene encargada una tarea, «arbitra y modera el funcionamiento regular de las instituciones», y esa tarea la cumple como persona no como institución mecánica. Es sabido que la mayoría de la doctrina opina que su actividad se concreta en las competencias que, entre otros, recogen los artículos 62 y 63 de la CE. Es obvio que nada hay que objetar a esta tesis, aunque también está claro que lo relevante, a nuestros efectos, estriba en cómo realiza el rey su cometido y no en el margen de discrecionalidad de que dispone para realizarlo, que es jurídicamente nulo por tratarse siempre de actos debidos. Pero, con todo, estamos ante la política constitucional y no frente a una categoría normativa-positiva, y el acento habrá que situarlo, por consiguiente, en la convicción personal con que el monarca desempeña la función constitucional de hacer converger los intereses plurales en una voluntad democrática compartida. Y el problema radica en que esa convicción debe coincidir necesariamente con el sentimiento de una sociedad que aspira a ser correctamente interpretada. La cuestión es de tino, de sensibilidad, de sintonía con el sentimiento democrático de la ciudadanía. Obviamente para ello se requiere una exquisita neutralidad y visión a largo plazo. Justamente dos condiciones que no parecen susceptibles de poder ser satisfechas igualmente cuando en el lugar del monarca se encuentra emplazado un presidente republicano. Su procedencia de la lucha política y la limitación temporal de su mandato cuestionan y degradan su apariencia, y sobre todo llegan a privarle potencialmente de la credibilidad en que un jefe del Estado neutral debe sustentar su comportamiento.

Así pues, la neutralidad del monarca es su gran atributo — su gran ventaja competitiva frente a un presidente electo — , junto con la estabilidad que transmite a la

${ }^{28}$ Cobra sentido aquí lo dicho anteriormente en relación con el juego institucional. El rey es en el juego político la única persona física que obra como tal, el resto son figuras representativas u órganos del Estado. Ello no se traduce en un mayor o menor grado de libertad de acción sino en el realismo que acompaña a su acción como ser humano y la proyección que esa acción tiene sobre la sociedad. La impronta que el monarca impone a sus actos marca un hito a todos los restantes actores políticos que siempre son presos de las circunstancias en que viven. El rey trasciende ese momento y está obligado a salir airoso de sus particulares circunstancias porque su función es a largo plazo. Justamente por eso se ve obligado a ser neutral, para no agotar su acción en un momento. También justamente por eso el monarca termina siendo responsable al cabo de los años de la marcha general del ciclo político que ha moderado desde su neutralidad. No hay pues monarcas irresponsables por mucho que lo diga la ley escrita. 
totalidad del sistema institucional la existencia de una magistratura vitalicia que, aspirando en sí misma a perdurar, consigue dar continuidad a la política en el tiempo. Una y otra ensambladas hacen factible la utilidad funcional del rey, que sobre todo es una persona. Pero neutralidad no significa neutralización y aquí estriba el lado positivo de la institución y también su gran riesgo. Un monarca neutral se comporta de manera neutralizada respecto de las partes de la sociedad pero no en relación con la Constitución. Su misión políticamente relevante es la de favorecer la integración democrática de las diferentes voluntades sociales y para eso debe operar constitucionalmente, comportarse dentro de la Constitución evitando con su acción pública que otros no lo hagan. En eso consiste ser neutral y eso mismo supone actuar correctamente, aunque sólo sea dando cuenta pública con su actitud de lo que está sucediendo en el momento oportuno. El límite entre lo que se puede hacer y lo prohibido es muy tenue en este punto. Pero existe y lo marca justamente la sinceridad que debe presidir la acción del monarca y el retrato que proyecta en la vida ciudadana de un menester en el que no cabe doblez. Una sinceridad que cuando existe logra contagiarse a todas las instituciones conjurando el riesgo de incurrir en una suerte de simulación colectiva en la que nada es lo que dice o aparenta ser. Justamente el gran riesgo que hoy afronta nuestra democracia.

Tal vez con la referencia a un caso concreto se entienda mejor lo que se pretende decir. Ese caso concreto son las vacantes que se producen en determinados órganos de dirección política cuando por ejemplo otro órgano constitucional que tiene encomendada la función de nombrar a sus miembros se demora en su provisión más allá del plazo previsto para su renovación. El problema se ha planteado en varias ocasiones con el Tribunal Constitucional y ahora mismo está sobre la mesa en la última fracasada renovación del Consejo General del Poder Judicial. Es cierto es que tras bastante discusión doctrinal se llegó al acuerdo de la necesidad de prorrogatio, que de otro lado derivaba de la propia naturaleza de estos órganos. Pero en cualquier caso la solución es imperfecta porque impide la imprescindible depuración y cambio de criterios que toda renovación de personas e ideas lleva implícita y que tan necesaria es en órganos que requieren de mantener gran coherencia con el sentir social. La pregunta que se impone es ¿Existe alguna forma de resolver el entuerto respetando la Constitución y sin forzar la competencia de los órganos que demoran están alcanzar el consenso necesario para este tipo de acuerdos?

La pregunta tiene respuesta en el hecho de que el rey es quien formalmente efectúa tales nombramientos y a diferencia de otros modelos como el alemán o el italiano, ni tiene legitimidad activa para acudir a ellos, ni dispone real y materialmente el nombramiento de sus miembros. ¿Podría el monarca alentar discretamente a los órganos renuentes en cumplir con sus obligaciones a aprestarse para hacerlo?

Por lo que hace a los problemas relacionados con el manejo efectivo del procedimiento recogido en el artículo 99 de la Constitución —que regula uno de los cometidos más identificativos y al tiempo más delicados y comprometedores para la neutralidad del monarca-, puede contribuir a ilustrar en términos muy concre- 
tos lo que se está intentando argumentar ${ }^{29}$. Y es que, desde las disposiciones de éste artículo, la función constitucional del rey no consiste bajo ningún concepto en intervenir políticamente en la negociación entre grupos con representación parlamentaria para construir el acuerdo interno que da pie a la investidura y que determina la formación de gobierno. Pero si pasa, sin la menor duda, por impedir (no prestándose a) que los intereses en juego terminen fraguando una simulación encaminada a aparentar como cierto lo que en el fondo sólo es una añagaza destinada a escabullir la obligada «accountability» (rendición de cuentas) de los partidos elegidos frente a la sociedad.

Estamos ante una cuestión terriblemente procelosa en la que la neutralidad activa del monarca debe plasmarse en dos direcciones: atenerse al mandato constitucional de no interferir la voluntad de la sociedad y evitar, con la sinceridad del propio comportamiento, que la monarquía pueda ser utilizada como burladero para amparar actitudes que tienen por objetivo fingir ante la opinión y en el fondo confundirla. El rey, en este caso, debe actuar con suma exquisitez permitiendo que los titulares del mandato popular se retraten en sus conductas tal y como auténticamente son, y no como desean aparecer. Es en la sincera actitud del rey donde estriba el punto de referencia desde el que la opinión puede llegar a formarse criterio acerca de cuándo un partido está efectuando un leal ejercicio de responsabilidad política y cuándo intenta eludir su representatividad resistiéndose a responder a las exigencias u obligaciones que las urnas le han impuesto. Un reto (dicho sea de paso no superable para un jefe de Estado electo) que en buena medida ha asomado ya en las dos últimas legislaturas y que nada tendría de extraño sí volviera a plantearse de manera más acusada en las que están todavía por venir.

En este sentido, como señala Miguel Revenga, todo indica que ciertos hábitos novedosos, incorporados hace dos años durante las consultas mantenidas por el monarca en relación con la propuesta del candidato a presidente del Gobierno - como el de dar sucinto conocimiento escrito a la opinión de lo tratado con los representantes políticos-, resultan extraordinariamente elocuentes. Y es que conviene no olvidar que la colosal mudanza a que asistimos en la vida social en la última década no ha venido acompañada de una paralela trasformación de las estructuras de representación política que sintonizando con la nueva complejidad emergente aspire a expresarla y encauzarla hacía el Estado, tal y como tradicionalmente venía haciendo el parlamento, sino que ha generado entre los actores políticos una dinámica de sobre-reacción que — como ha recordado entre nosotros Juan Linz acudiendo al término «responsividad»— en muchos casos únicamente aspira a diferir e incluso a difuminar toda responsabilidad política, presentando teatralmente la rapidez en la respuesta como una rendición de cuentas que en verdad se busca orillar. La función del rey neutral no es

${ }^{29}$ Sobre esta cuestión, muy recientemente, vid. Aranda Álvarez, E., Lecciones constitucionales de 314 días con el Gobierno en funciones, Tirant lo Blanch, 2017. Especialmente la Primera parte, sobre «La posición del Rey en el procedimiento de investidura del Presidente del Gobierno», con trabajos del Torres del Moral, Satrústegui y Ripollés. 
gobernar, pero tiene que ver con que aquellos que están llamados a hacerlo no se sirvan del juego institucional de la monarquía para eludir su propia responsabilidad política, y sí lo hacen que su conducta quede de manifiesto ante la sociedad.

Más allá de ello y tomando como referencia el supuesto contrario, un monarca neutralizado no cumple ninguna función, se encuentra al margen del proceso político, ni siquiera sirve de cauce, sólo es símbolo mudo y frio. Lo que implica que no tiene encomendado velar para favorecer el acuerdo dentro del marco estricto de la norma constitucional. Sólo el rey neutral está llamado por la Constitución a propiciar un correcto funcionamiento de los mecanismos institucionales democráticos y a asumir como persona una función de integración colectiva que redunde en una mayor estabilidad para la sociedad. El rey neutral desempeña un cometido que puede caracterizarse en las siguientes notas.

a. El rey es un polo de referencia independiente y se trata del único órgano que - salvo el supuesto excepcional del art 57.3 CE — no depende de ningún otro para la provisión de su magistratura que además es de duración incierta.

b. El rey marca su propio Tiempo y no está condicionado por el tiempo político de los demás órganos.

c. El obrar del rey está sujeto a su credibilidad y a la inversa, su manera de obrar alimenta su mayor o menor credibilidad.

d. El rey es constitucionalmente autónomo, es decir tiene determinadas atribuciones constitucionales superiores relacionadas con el Estado y relativas a toda la comunidad nacional, para asegurar la continuidad de la política, que están por encima de todas las funciones, incluida la ejecutiva y que atienden al funcionamiento regular de sus órganos.

e. El rey está separado del gobierno y no se encuentra incardinado en el poder ejecutivo ni participa de la función de gobierno, pero si tiene atribuciones constitucionales que se identifican con el Estado y que se concretan en lo dispuesto por el art. 62 y 63.

f. No dispone de poder de reserva (poderes implícitos) que son radicalmente incompatibles con su sometimiento a la Constitución. No puede alargar competencias que constitucionalmente no le corresponden, pero si profundizar en las que le han sido encomendadas, ya que quien tiene una atribución debe tener igualmente la necesaria para preparar esa atribución (los llamados poderes instrumentales).

g. El rey tiene que ser consultado por el gobierno en la definición de las opciones y orientaciones políticas del Estado en las que el gobierno debe prestarle la debida consideración (due attention), ya que su definición no corresponde exclusivamente al gobierno sino a las Cortes y al propio rey.

h. El rey contribuye al control social del gobierno y especialmente frente a mayorías prepotentes, en este sentido su tarea consiste en posibilitar encontrar soluciones constitucionalmente adecuadas y políticamente coherentes, para 
afrontar los problemas concretos y conflictos en momentos de formación de la voluntad del Estado.

i. Del mismo modo pero en sentido inverso, el rey tiene el deber de facilitar la integración política y contribuir a la construcción del consenso, especialmente en aquellos casos en que la resistencia al acuerdo entre los diferentes grupos políticos pone en peligro la estabilidad de las instituciones y el propio juego democrático.

j. Tiene una posición supra-partes que le ayuda a promover la moralidad de la acción y de conducta pública y a apaciguar y dirimir los conflictos políticos y sociales, atemperando las situaciones de crisis y de impase institucional.

k. Tiene también el poder genérico de tomar posiciones públicas en tanto jefe del Estado a través de discursos entrevistas y actos oficiales en el ejercicio de los poderes constitucionales de jefe del Estado que no debe sobrepasar los propios de una magistratura de influencia.

1. Posee la facultad discrecional de asistir a los Consejos de Ministros a invitación del presidente y presidirlos con la consiguiente desvalorización del presidente, y ni el Presidente encuentra obligado, a solicitar, ni el rey tiene obligación de corresponder a la solicitud; la Constitución es muy clara en el apartado g del art. 61 y por supuesto aquí no cabe hablar de refrendo.

Title:

The King in the Constitution of 1978: the role of the Monarchy in a Democracy with claim of veracity.

\section{Summary:}

IT'S POSSIBLE A KING IN DEMOCRACY? A. The monarchy as democratic absurdity, its nonsense in an igualitary society. B. The Monarchy legitimacy and credibility in the current Spanish democratic moment. C. The Monarchy in a Constitution that emerged as an «evolutionary achievement». II. SPANISH PARLIAMENTARY MONARQUY IN ITS CONCRETE MEANING. A. Monarchy and political modernity: The Monarchy legitimacy and identity 1 . The king as a life-vital and institution. 2. The king as an expression of a monopolize political State. 3. The duties of the neutral king in a democratic Constitution. III. THE MONARCHY'S STRUCTURE AND DEMOCRATIC FUNCTIONALITY. A. The Abduction as an extraordinary mechanism of responsibility 
and the constitutional status of the king. B. The acts of the monarch in relation to the other constitutional organs. Article 99 of the Constitution.

\section{Resumen:}

El trabajo trata de explicar que la única fundamentación de la monarquía española es su funcionalidad democrática, de manera que el rey desempeñe su doble labor de integrar el consenso y de mejorar el rendimiento de las instituciones del Estado mejor que un presidente de la República. El rey debe obra con neutralidad asegurando desde su condición neutral el buen funcionamiento de la democracia. Para ello debe ser creíble.

\section{Abstract.}

The study tries to explain that the only Spanish monarchy fundamentation is its democratic functionality, so that the king performs his dual task of integrating consensus and improving the performance of State institutions better than a Republic President. The king must act with neutrality ensuring from his neutral condition the proper functioning of democracy. To do so he must be credible.

\section{Palabras clave.}

Rey neutral; credibilidad; legitimidad; función; democracia; consenso; neutralidad.

\section{Keywords.}

Neutral King; Credibility; Legitimacy; Function; Democracy; Consensus; Neutrality. 